\title{
INVESTIGATION OF CREATED FRACTURE GEOMETRY THROUGH HYDRAULIC FRACTURE TREATMENT ANALYSIS
}

\author{
A Thesis \\ by \\ IBRAHEEM ANWER AHMED
}

\begin{abstract}
Submitted to the Office of Graduate Studies of Texas A\&M University

in partial fulfillment of the requirements for the degree of

MASTER OF SCIENCE
\end{abstract}

Approved by:

Chair of Committee, Christine Ehlig-Economides

Committee Members, Peter Valko

Yuefeng Sun

Head of Department, $\quad$ Alfred Daniel Hill

December 2012

Major Subject: Petroleum Engineering

Copyright 2012 Ibraheem Anwer Ahmed 


\begin{abstract}
Successful development of shale gas reservoirs is highly dependent on hydraulic fracture treatments. Many questions remain in regards to the geometry of the created fractures. Production data analysis from some shale gas wells quantifies a much smaller stimulated pore volume than what would be expected from microseismic evidence and reports of fracturing fluids reaching distant wells. In addition, claims that hydraulic fracturing may open or reopen a network of natural fractures is of particular interest.

This study examines hydraulic fracturing of shale gas formations with specific interest in fracture geometry. Several field cases are analyzed using microseismic analysis as well as net pressure analysis of the fracture treatment. Fracture half lengths implied by microseismic events for some of the stages are several thousand feet in length. The resulting dimensions from microseismic analysis are used for calibration of the treatment model. The fracture profile showing created and propped fracture geometry illustrates that it is not possible to reach the full fracture geometry implied by microseismic given the finite amount of fluid and proppant that was pumped. The model does show however that the created geometry appears to be much larger than half the well spacing. From a productivity standpoint, the fracture will not drain a volume more than that contained in half of the well spacing. This suggests that for the case of closely spaced wells, the treatment size should be reduced to a maximum of half the well spacing.
\end{abstract}


This study will provide a framework for understanding hydraulic fracture treatments in shale formations. In addition, the results from this study can be used to optimize hydraulic fracture treatment design. Excessively large treatments may represent a less than optimal approach for developing these resources. 


\section{DEDICATION}

This thesis is dedicated to my family who encouraged me to pursue graduate studies and supported me throughout my education. 


\section{ACKNOWLEDGEMENTS}

I would first like to acknowledge my professor Dr. Christine Ehlig-Economides. It was a great learning experience working with her and I truly appreciate the time she spent advising me. I would also like to thank Dr. Peter Valko whose fracturing course is perhaps unparalleled at the university level. Lastly, I thank all of my fellow research group members for the useful discussions that we had.

Thanks to the Crisman Institute who provided the funding for this research project. Also thanks to Kappa and FracproPT for providing their software for academic use. 


\section{NOMENCLATURE}

$\begin{array}{ll}\sigma_{\min } & \text { Minimum horizontal stress } \\ \text { FCT } & \text { fracture calibration test } \\ { }^{\circledR} & \text { Registered trade mark } \\ \text { CLE } & \text { composite layering effect } \\ \text { bbl } & \text { U.S. Petroleum Barrel } \\ \mathrm{x}_{\mathrm{f}} & \text { hydraulic fracture half-length } \\ \mathrm{h}_{\mathrm{f}} & \text { hydraulic fracture height }\end{array}$




\section{TABLE OF CONTENTS}

Page

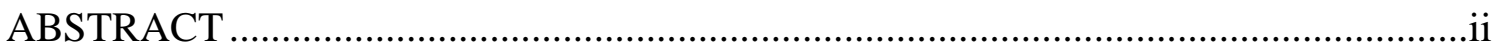

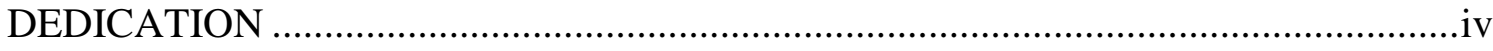

ACKNOWLEDGEMENTS ……………………………………………………...

NOMENCLATURE .................................................................................................

TABLE OF CONTENTS …………………………..................................................vii

LIST OF FIGURES ………………………………….......................................

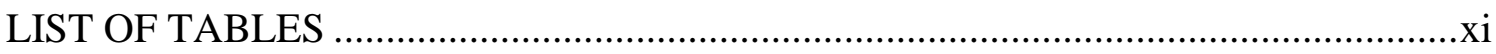

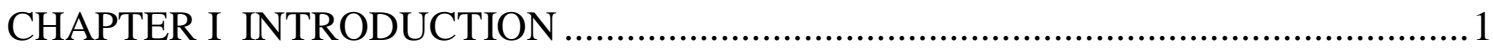

CHAPTER II BACKGROUND/LITERATURE SURVEY .............................................

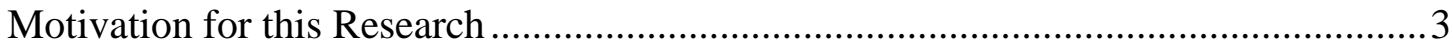

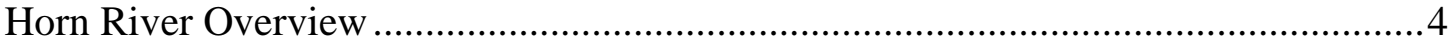

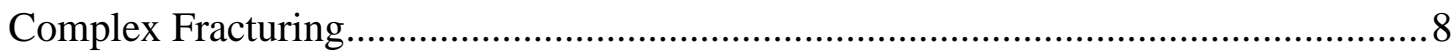

Microseismic Analysis ................................................................................. 10

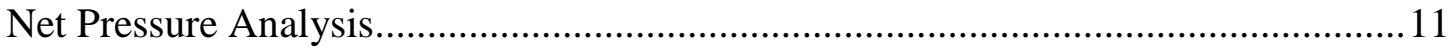

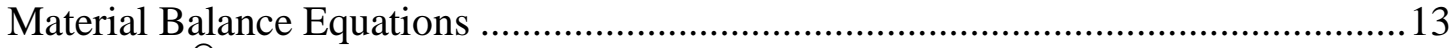

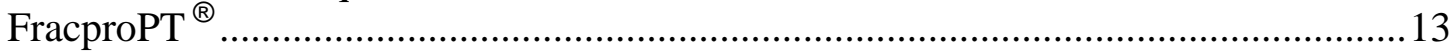

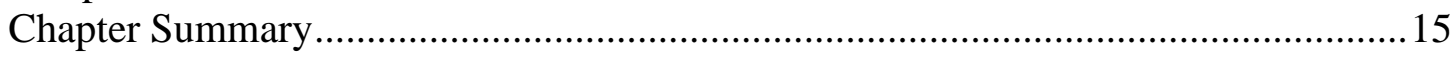

CHAPTER III MICROSEISMIC ANALYSIS ......................................................... 16

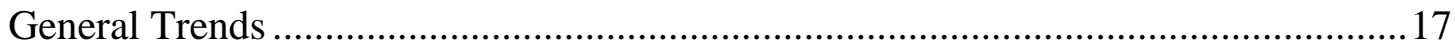

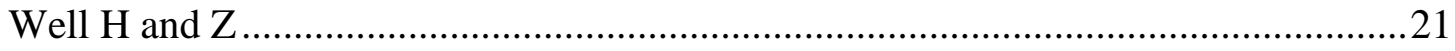

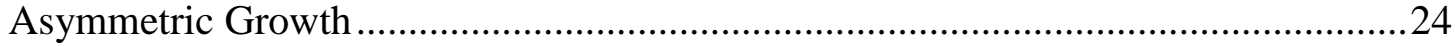

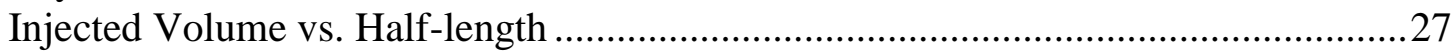

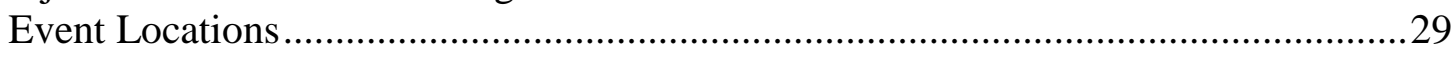

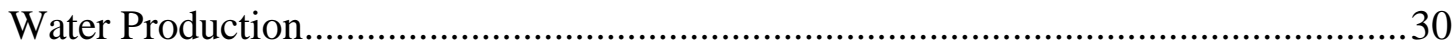

vii 


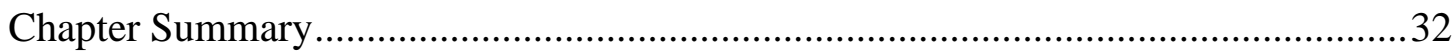

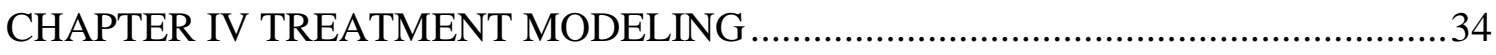

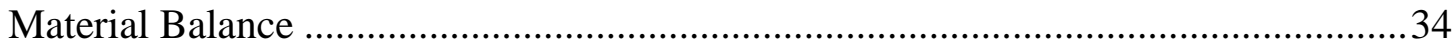

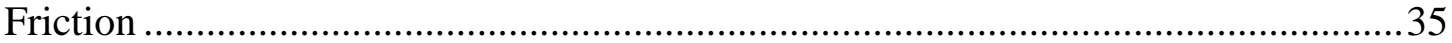

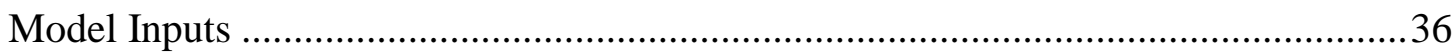

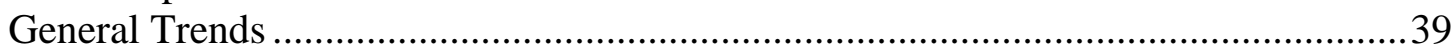

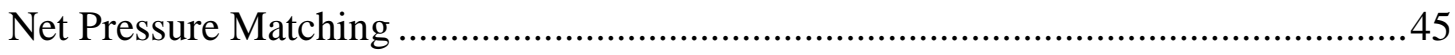

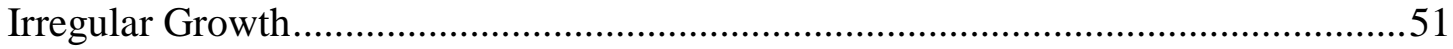

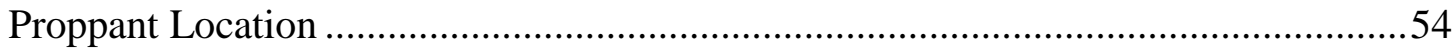

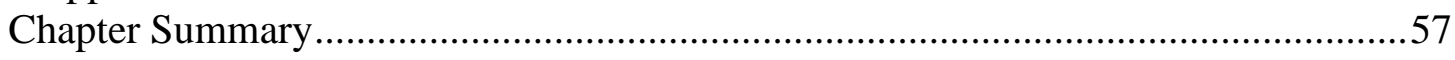

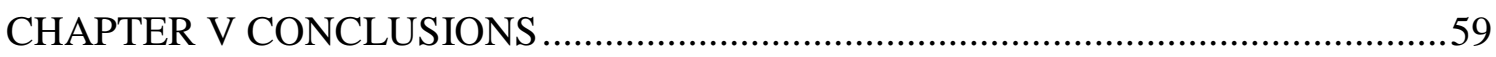

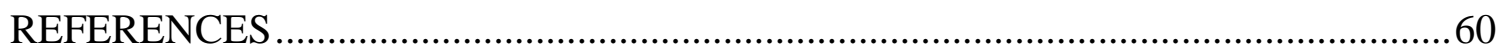

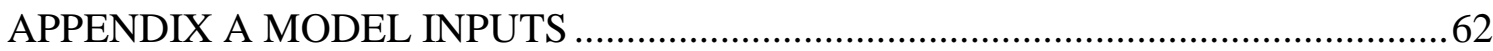




\section{LIST OF FIGURES}

Page

Figure 1 - Horizontal well with multiple fractures (modified from PETE 648 notes).......4

Figure 2 - Zones of interest in Horn River field (Beaudoin et al.) .................................6

Figure 3 - Schematic of Horn River pad ................................................................. 7

Figure 4 - Nolte-Smith net pressure analysis plot (Economides and Martin, 2008) ........ 12

Figure 5 - Cross section view of all stages monitored by microseismic .........................18

Figure 6 - Fracture half lengths observed by microseismic monitoring....................... 19

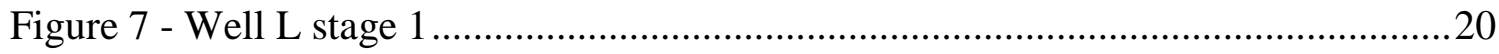

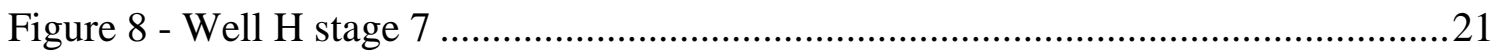

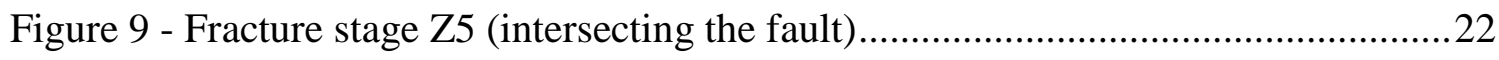

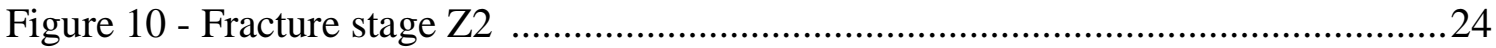

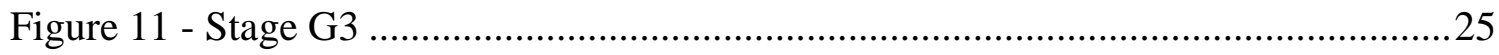

Figure 12 - Stage 5 of well O, mapped fault shown by black dashed line .....................26

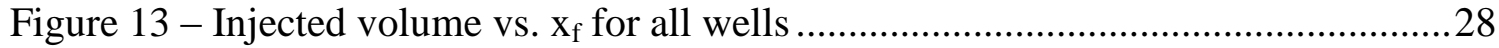

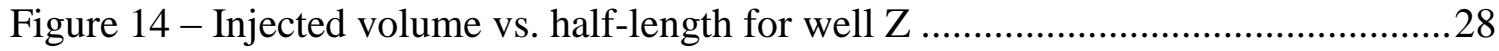

Figure 15 - Injected volume vs. half-length for well H........................................29

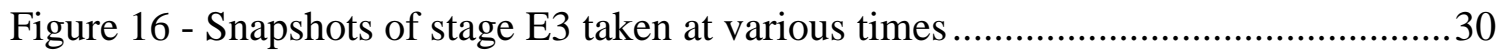

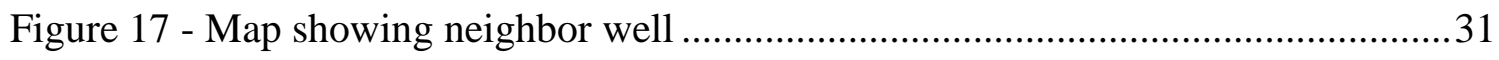

Figure 18 - Cumulative water production for wells A, C, and E............................... 32

Figure 19 - Perforation design for Horn River wells ............................................. 36

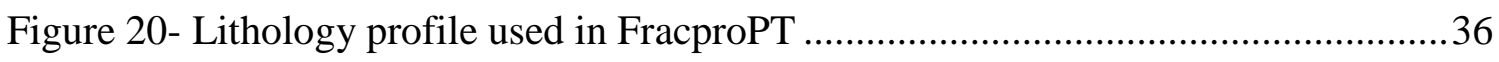




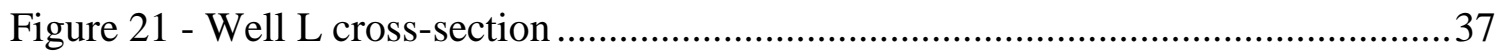

Figure 22 - Production $\log$ for well C .............................................................................39

Figure 23 - Observed net pressure for well J .............................................................40

Figure 24 - Observed net pressures for well D........................................................... 41

Figure 25 - Log-log plot of well J net pressures ........................................................42

Figure 26 - Log-log plot of well D net pressures .........................................................4

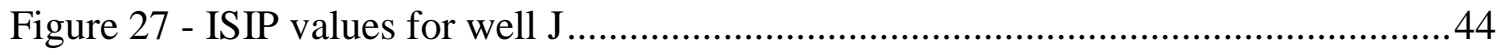

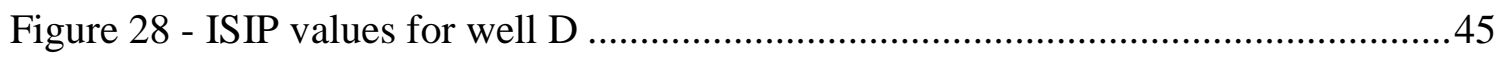

Figure 29 - Perforation clusters for stage L1 ……......................................................46

Figure 30 - Net pressure match for stage L1 ...........................................................46

Figure 31 - Fracture profile for stage L1 ……………............................................

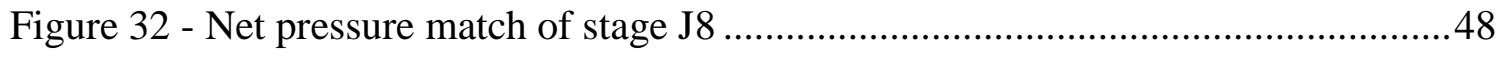

Figure 33 - Fracture profile, J8 ...............................................................................

Figure 34 - Net pressure match stage A4 ……………...........................................50

Figure 35 - Stage A4 fracture profile …………………………………....................51

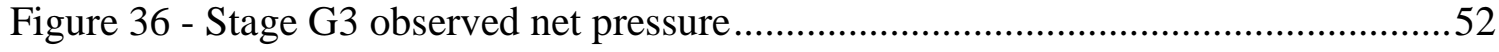

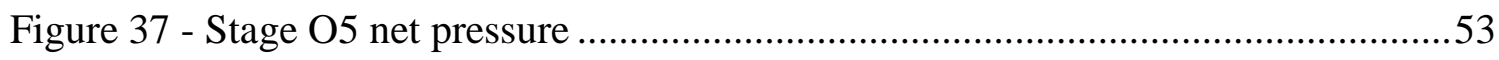

Figure 38 - Stage J8 proppant location......................................................................55

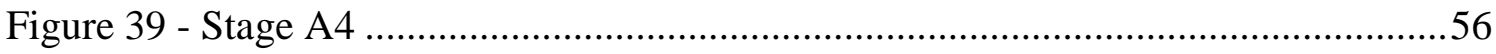




\section{LIST OF TABLES}

Page

Table 1 - Explanation of Nolte-Smith Plot.............................................................. 12

Table 2 - Input for Multiple Fractures feature stage L1A ........................................62

Table 3 - Input for Multiple Fractures feature stage J8 ......................................6 62

Table 4 - Input for Multiple Fractures feature stage A4 ........................................62

Table 5 - Input for Multiple Fractures feature stage L1A ........................................62 


\section{CHAPTER I}

\section{INTRODUCTION}

The two main technologies driving the success of shale gas development are horizontal completions and hydraulic fracturing. Due to economic factors such as a low commodity price, optimized recovery of these resources is needed in order to make a project economically viable. Fisher et al. (2004) indicated a lack of correlation between horizontal well length and well productivity. Therefore the focus on optimizing shale gas completions has shifted towards understanding and optimizing the hydraulic fracture.

This study begins with a thorough analysis of microseismic events recorded for the given field data set. Fracture geometry estimates from the microseismic analysis are used to calibrate the treatment modeling. The next stage of the project uses net pressure matching as a tool for fracture treatment modeling. After removing all frictional effects from the surface recorded data, the observed net pressure curve is presented in order to identify the overall behaviors during the fracture treatment.

The objective of this research is to estimate created fracture geometry using both microseismic analysis and treatment modeling. Differences between these estimates as well as the implications for well productivity are discussed.

The thesis is organized into five chapters as follows:

Chapter I: Introduction - This chapter will discuss the problem statement and objectives. It will include a brief section on methodology, explaining how we approach the problem. Lastly, it will give the reader an overview of the study highlighting the main points. 
Chapter II: Literature Survey - This chapter will present a summary of previous work relevant to this study. Subject areas that will be discussed in detail include microseismic analysis, complex fracturing and pseudo 3D simulation of hydraulic fracturing. This chapter will end with an overview of the Horn River data set used in this study.

Chapter III: Microseismic Analysis - This chapter will include a detailed discussion of findings from the microseismic analysis of the Horn River treatments. The discussion will conclude with a summary highlighting key parameters from the analysis which will be used to calibrate the treatment modeling.

Chapter IV: Treatment Modeling - This chapter will be the main focus of the study. The chapter will begin with discussing the Nolte-Smith plot and the overall trend observed in the data. A discussion of the basic material balance equations used for hydraulic fracture analysis and example calculations will be presented. The procedure for net pressure matching using pseudo 3D simulators will be explained. Several examples of net pressure matches will be shown. Different scenarios of how the injected fluid and Proppant could reside in the stimulated volume will be explored.

Chapter V: Conclusions - This chapter will compare the results of microseismic analysis with treatment analysis. Any discrepancy between the two analyses will be explained. Lastly, the results from PTA and PDA will also be discussed briefly. 


\section{CHAPTER II}

\section{BACKGROUND/LITERATURE SURVEY}

This chapter will provide the necessary background information needed for this study. A brief motivation for this research work will be presented followed by a description of the field data set to be used. Complex fracturing is discussed due to its association with shale fracturing in the literature. The two analysis techniques used to estimate created fracture geometry are presented. Lastly, an overview is given of the commercial fracture simulator used in this study.

\section{Motivation for this Research}

Optimization of the hydraulic fracture treatment requires accurate information regarding the created fracture geometry. Often times, there are discrepancies between the various analysis methods in regards to the size of the created fracture. Barree et al. (2005) showed examples illustrating that the created fracture dimensions are much smaller than those expected during the design stage. Song et al. (2011) also showed that the hydraulic fracture size estimated from production data analysis for the Fayetteville and Haynesville shales was about $20 \%$ of the horizontal well spacing. Yet another method of analysis, microseismic analysis also leads to varying conclusions. Many times the cloud of microseismic events spans over the entire pad implying a fracture halflength of several thousand feet. Lastly, fracture modeling which is based on material balance of fluid and proppant injected also leads to different results.

These varying estimates of fracture size can be very confusing for operators. Reliable estimates of fracture length are necessary to optimize hydraulic fracture design. 
One possible reason for these discrepancies is fracture complexity. This study investigates fracture complexity as a means to explain how the injected volume may reside within the shale formation.

\section{Horn River Overview}

A typical shale gas completion consists of a horizontal well drilled in the direction of $\sigma_{\min }$, which is the least principal horizontal stress. After drilling the lateral, the well is divided into various stages consisting of 1 or more perforation clusters. Each stage is hydraulically fractured in isolation of other stages resulting in one or more transverse fractures. If the horizontal well was truly drilled in the direction of least principal stress, the fractures will be perpendicular to the well due to the fact that the fracture will naturally open against the least principal stress. Figure 1 shows a schematic of a horizontal well with multiple fractures. The right side of the Figure is a zoom-in showing one fracture opening against the least principal stress.

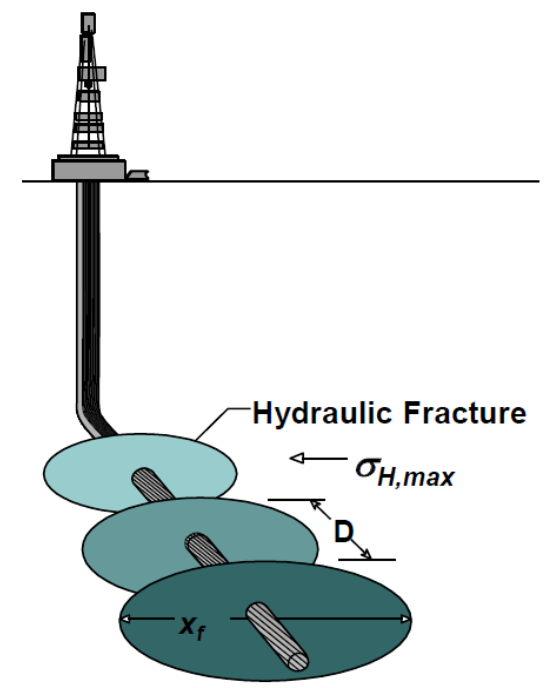

\section{Least Principal Stress}

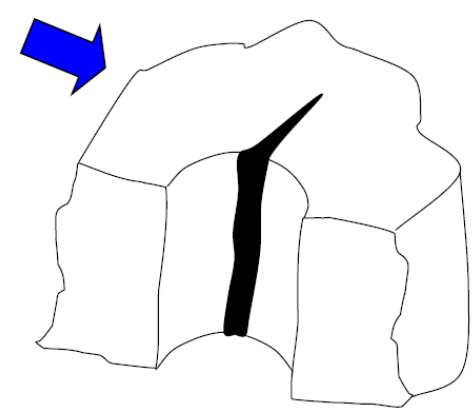

Figure 1 - Horizontal well with multiple fractures (modified from PETE 648 notes) 
The data set for this study comes from the Horn River shale play. The Horn River shale play is located on the northern border between British Columbia and the North West Territories, Canada, approximately 750 miles northwest of Edmonton, Alberta. Field development primarily targets two main formations from the Middle and Upper Devonian periods, known as Muskwa and Otterpark, where deposits are described as grey to black organic rich shales. In addition to these two major zones of interest, operators have also been interested in developing the Klua/Evie formation which is below the Otter Park. Figure 2 is a well log from the Horn River field in which the zones of interest are shown. In addition, the Ft. Simpson and Keg River formations are shown as frac barriers which are about 200 meters apart in the given log (Beaudoin et al., 2011). The Ft. Simpson formation is composed of grey shale and mudstone. The shale can be calcareous, silty or sandy. The Keg River formation is composed of dark dolomite with inter-crystalline or vuggy porosity and wackestone limestone. It should be noted that this particular log is not from the same pad which is discussed in this study. 


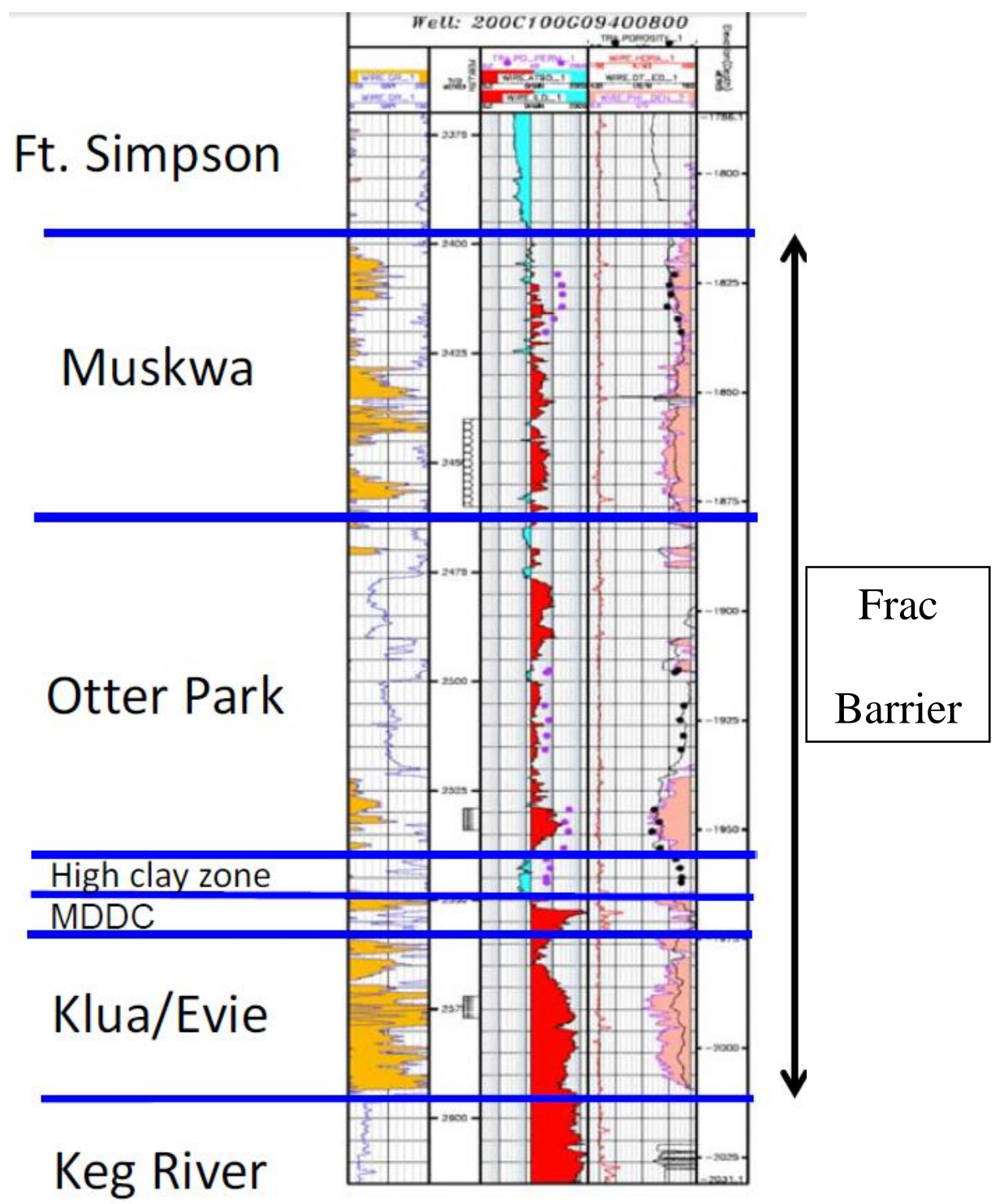

Figure 2 - Zones of interest in Horn River field (Beaudoin et al.) 


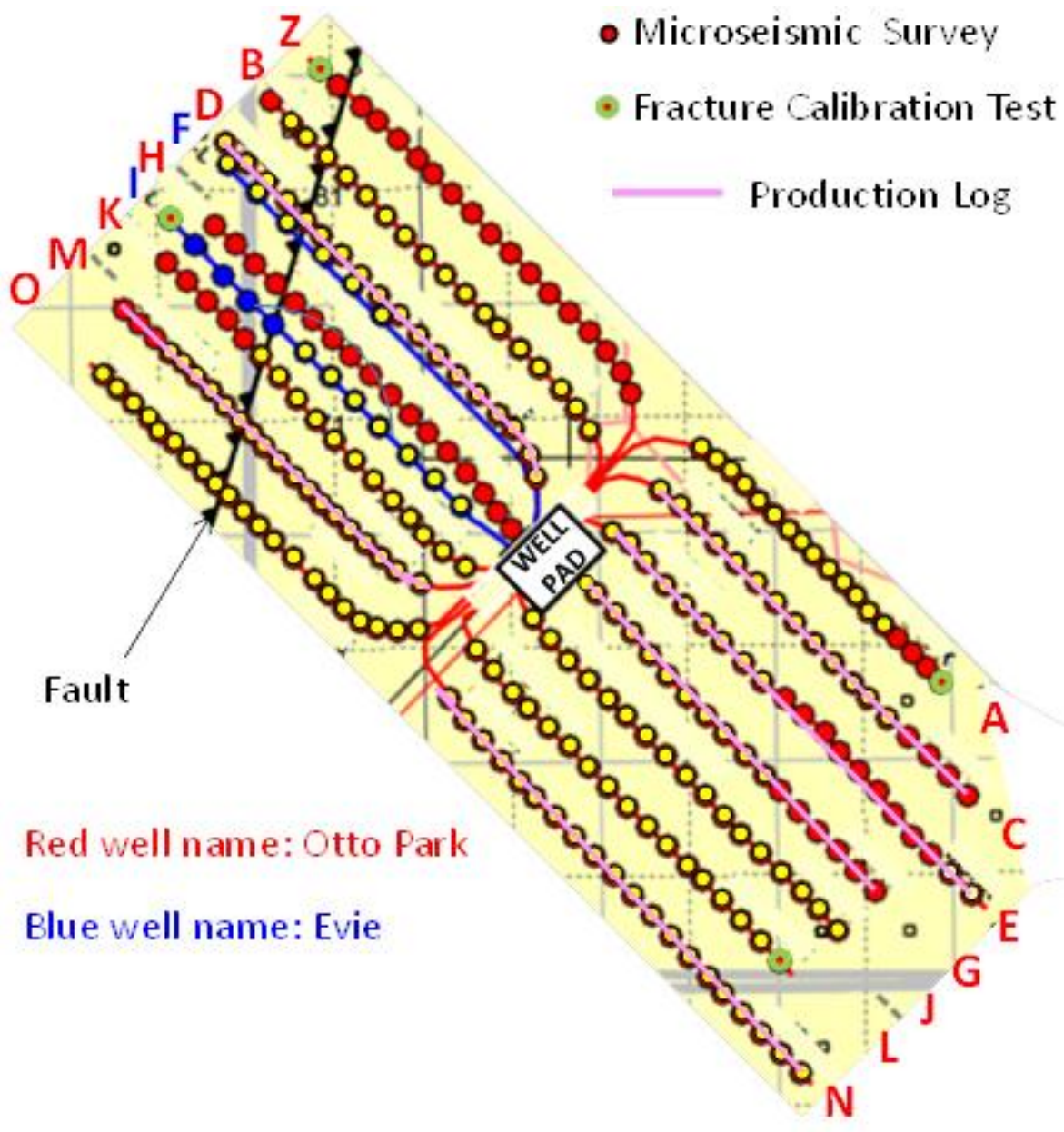

Figure 3 - Schematic of Horn River pad

Production data analysis as well as pressure transient analysis has been conducted for the Horn River dataset. Ehlig-Economides et al. (2012) presented an integrated analysis of 16 horizontal wells with multiple transverse fractures from the Horn River Shale play. The study combined many different analyses including pressure transient analysis, production data analysis, fracture calibration test and hydraulic fracture treatment analysis. This study focuses on the hydraulic treatment analysis that was briefly discussed in the previous paper. A schematic of the pad which was used in 
this study is shown in Figure 3. All of the wells colored in red were completed in the Muskwa/Otterpark formation. The wells colored in blue were completed in the Evie formation. The black line passing through the left side of the pad is a major mapped fault which extends further north and south of the pad.

Another companion study was conducted by Hurd and Zoback (2012) which focused on the geomechanics and microseismicity of the Horn River shale. Their paper includes a thorough discussion about earthquake characterization using b-values. They show that the b-values recorded for the Horn River treatments are higher than the bvalues for naturally occurring earthquakes. This would indicate that fault deformation is occurring in addition to propagation of the main hydraulic fracture. The authors also discuss calculation of $\sigma_{\min }$ using the Instantaneous Shut-In Pressure (ISIP) determined from surface recorded pressure. Using this technique, they have shown higher values for $\sigma_{\min }$ in the wells surrounding the fault. In addition, they state that the values of ISIP are increasing within the same well as the treatments progress from the toe to the heel of the horizontal well. It is important to note here that the values used by the authors for ISIP were taken from surface readings and the effect of friction was not taken into account. The authors did not engage in any discussion of created fracture size. Hydraulic fracture size resulting from microseismic analysis will be discussed in this study.

\section{Complex Fracturing}

Complex fracturing is a loosely used term in the oil and gas industry. Some authors use the term complex fracturing to signify propagation of multiple fractures resulting in higher treating pressures (Davidson et al., 1993). More recently other authors 
have associated complex fracturing with the re-activation of natural fractures (Gale, 2011). In both of these cases, complex fracturing is associated with a pre-existing natural fracture network.

When considering the case of complex fracturing, the fracture fluid efficiency must also be considered. It has been shown by several authors that the majority of shale plays have very low permeability in the nano-darcy range. For this reason, fracture calibration test interpretations in shale gas wells have estimated high fluid efficiency (Mohamed et al., 2011). If the assumption is that the natural fracture network is open (and empty) prior to the hydraulic fracture treatment, very low fluid efficiency should be observed due to the high amount of fluid that would leak-off into the natural fractures.Warpinski (1991) however states that high leak-off might not be seen by the fracture calibration test. He cites an example where the natural fractures are pressure sensitive and only opened under high injection pressure. At higher pressures, the leak-off coefficient maybe $35 \%$ greater than what was initially seen by the fracture calibration test (FCT).

Gale (2011) also mentioned a similar point when discussing the reactivation of natural fractures. She mentioned that the natural fractures are sometimes filled with a calcium carbonate material. However, the pressure required to open the natural fractures is much less than that required to fracture new rock. This implies that high efficiency would be seen initially until the natural fracture network is reactivated.

Proppant placement is also an issue of concern when discussing complex fracturing. Even if the pad fluid creates complex fractures, what happens to the large 
amount of proppant that is injected into each fracture? Many operators often pump a stage of very fine 100 mesh proppant followed by a larger diameter 40/70 proppant. Warpinski (1991) presented a case study of a hydraulic fracture treatment in the Mesaverde formation in order to "preserve the permeability of the fissures while reducing leak-off." It should be noted that application of 100 mesh discussed by Warpinski was for tight sands not for shale formations.

Various analysis techniques have been discussed in the literature to diagnose complex fracturing. On an experimental level, Warpinski and Teufel (1987) first discussed mineback experiments studying the propagation of hydraulic fractures. A mineback experiments is when a hydraulic fracture is pumped into a rock simulating the in-situ conditions. The rock is then excavated to observe the fracture directly. They specifically examined the effect of geological discontinuities on fracture propagation. In the field, assessing fracture complexity is more challenging. Cipolla et al., 2010 proposed a form of net pressure for diagnosing fracture complexity (Cipolla et al., 2010). Another technique being used to diagnose fracture complexity is microseismic analysis.

\section{Microseismic Analysis}

Microseismic analysis has been used extensively to understand created fracture geometry. Fisher et al. (2004) used microseismic analysis to investigate hydraulic fracturing in the Barnett shale. Gale (2007) reported natural fractures in the Barnett Shale but also indicated that they tend to be cemented and not conductive to flow. Fisher interpreted the microseismic events observed during hydraulic fracturing as a network of fractures. Moreover, he established that the productivity of the well is more dependent 
on the created network than the horizontal well length or even the amount of fluid injected.

In addition to identifying fracture complexity, microseismic data have also been used to study the height growth of the hydraulic fracture. Cipolla et al. (2009) presented a case where the microseismic analysis was used as a basis for confining the hydraulic fracture treatment during modeling. Often times the stress contrast generally needed for fracture models to confine height growth is not present. Microseismic data may show apparent height confinement due to other lithological reasons. Cipolla et al. (2009) suggest that the treatment model should be calibrated using the microseismic data.

\section{Net Pressure Analysis}

Net Pressure analysis is an important tool in understanding hydraulic fracture propagation. This technique was first suggested by Nolte (1979 and 1988). Net pressure is the pressure which drives hydraulic fracture growth. It is defined as the total pressure inside the fracture minus the closure stress (rock stress acting to close the fracture). When pumping an actual treatment, often pressures are recorded on the surface and the net pressure is calculated used the following equation:

$$
P_{\text {net,observed }}=P_{\text {surface }}+P_{\text {hydrostatic }}-\Delta P_{\text {friction }}-\sigma_{\text {closure }}
$$

When the net pressure is plotted on a log-log plot, the slope of the curve can be used to understand what phase of propagation the treatment is undergoing. Figure 4 below shows the Nolte-Smith net pressure analysis plot presented in the book Modern Fracturing by Economides and Martin (2008). 


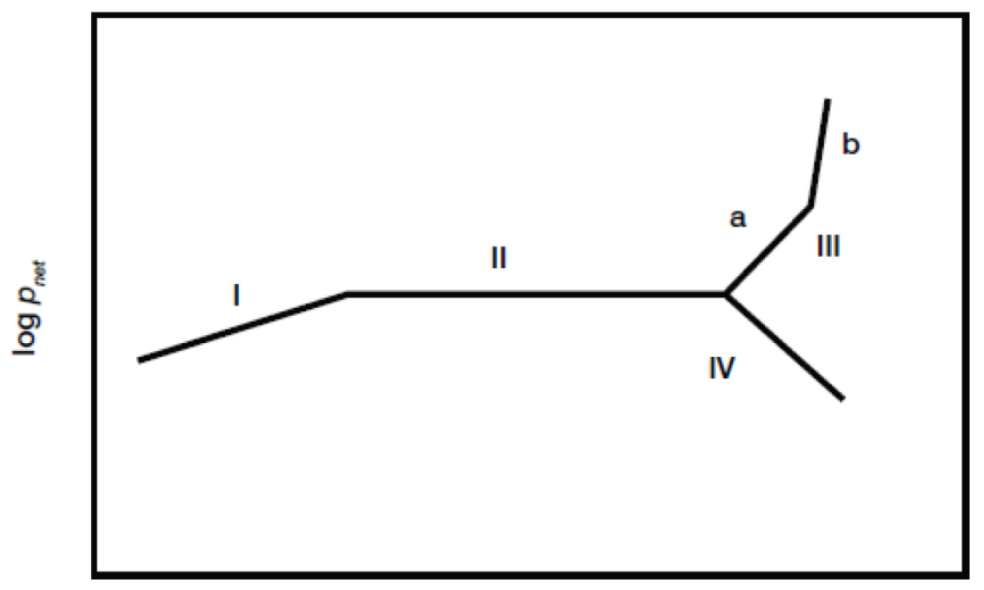

$\log t$

Figure 4 - Nolte-Smith net pressure analysis plot (Economides and Martin, 2008)

Table 1 gives an explanation of the different behaviors seen in Figure 2. It is important to note that this net pressure analysis plot is mainly designed for use with PKN type fractures in which the fracture length is considerably higher than fracture height.

\begin{tabular}{|c|l|}
\hline Mode & Behavior \\
\hline I & $\begin{array}{l}\text { Propagation with PKN fracture geometry. Gradient } \\
\text { is equal to e (see Eq. 4-16) for constant frac fluid } \\
\text { rheology. }\end{array}$ \\
\hline II & $\begin{array}{l}\text { Constant gradient }=0 \text {. Represents height growth } \\
\text { in addition to length growth, or increased fluid loss, } \\
\text { or both. Can also be explained by a change in the } \\
\text { relationship between } p_{\text {net }} \text { and } w_{f} \text { (see Eq. } 4-5 \text { - this } \\
\text { implies a change in rock mechanical characteristics). }\end{array}$ \\
\hline IIIa & $\begin{array}{l}\text { Unit slope. This means that } p_{\text {net }} \text { is now directly } \\
\text { proportional to time (and also to rate, as this is } \\
\text { usually constant with respect to time). This behavior } \\
\text { is usually associated with additional growth in } w_{f} \\
\text { such as during a tip screenout (see Section 4-7.3.2). }\end{array}$ \\
\hline IIIb & $\begin{array}{l}\text { Slope }>2 \text {. Screenout, usually a near-wellbore event } \\
\text { with a very rapid rise in pressure. }\end{array}$ \\
\hline IV & $\begin{array}{l}\text { Negative slope. Rapid height growth. Potentially } \\
\text { KGD or radial fracture geometry. }\end{array}$
\end{tabular}

Table 1 - Explanation of Nolte-Smith plot from Modern Fracturing (table 4.2) 


\section{Material Balance Equations}

In addition to identifying the overall trends in the net pressure plots, this study also analyzes the treatments from a material balance stand point. Ehlig-Economides et al. (2012) showed a fracture fluid efficiency of $92 \%$ for the Horn River wells based on fracture calibration tests. Well logs available in the literature as well as in the given data set show that formations that may act as barriers to fracture growth are greater than 800 $\mathrm{ft}$ apart. No other significant stress contrasts are seen in the zones of completion. This suggests the possibility of radial fracture growth.

\section{FracproPT $^{\circledR}$}

FracproPT ${ }^{\circledR}$ is one of the commercially available software packages for 3D modeling of the hydraulic fracture treatment. The reason for selecting this particular software package was due to two unique features it contains: "Multiple Fractures" and “Composite Layering Effect." As mentioned previously, the treating pressures observed in the field are often times much higher than the pressure a conventional fracture treatment model would predict. One way to reconcile the excess net pressure is to use the multiple fractures feature. This feature offers a way to simulate complexity as creation of multiple fractures. The logic behind this is that multiple fractures propagating in the same vicinity and therefore competing in growth will result in a higher net pressure.

Caution must be used when entering values for "volume factor" and "opening factor" required for this feature. The software developers have explained that increasing 
the numerical value implies greater complexity during the treatment, but the exact number is of no particular significance and does not correspond to the number of fractures being created.

The other unique feature is the Composite Layering Effect (CLE). The CLE controls fracture height growth. Normally, fracture height growth is dependent on the stress profile input from well logs. In some cases, microseismic analysis indicates height confinement even though there is no stress contrast shown by the rock properties. In this case, the CLE may be used to confine the fracture height. This will also result in a slight increase in net pressure. This feature should not be used unless there is clear indication of height confinement based on microseismic analysis.

While discussing the reservoir parameters, one must also consider how the net pressure is calculated. In FracproPT ${ }^{\circledR}$, the net pressure is calculated using only the closure stress for the layer in which the perforations are contained. If the value of closure stress is changed only in this layer, the "Observed Net Pressure" curve will change substantially. In contrast, changing the stress in any of the other layers will not affect the net pressure calculation.

The treatment schedule as pumped in the field is input into FracproPT ${ }^{\circledR}$ using a database file (DBS). The actual rates, concentrations and volumes pumped in the field are input into the software. Injection staging must be set using the measured data curve. Different injection stages are needed only when the stage type changes, for example pad to slurry. Within the slurry stage, the software automatically uses the measured data in 
the field to determine the proppant concentration. Different stages are not needed for changing proppant concentrations.

One of the last steps in net pressure matching is adjusting the fraction factor. When trying to match the simulated net pressure to the observed net pressure during pumping, we must first remove all friction pressure from the measured pressure data. The friction term is calculated using the equation below:

$\Delta P_{\text {friction }}=\Delta P_{\text {wellbore }}+\Delta P_{\text {perfs }}+\Delta P_{\text {near-wellbore }}$

If the friction is modeled incorrectly, the observed net pressure curve will contain step changes whenever the injection rate changes abruptly. When correcting for friction, the goal is to have a smooth pressure curve over periods of abrupt flow rate changes. Two main friction terms used in the simulator are perforation friction and near wellbore friction. This must account for known perforation size and density values that may be different for every hydraulic fracture stage in a multiple transverse fracture horizontal well.

\section{Chapter Summary}

Treatment modeling and microseismic analysis are both used by the industry for estimating hydraulic fracture geometry. Both of these analysis techniques will be used for the Horn River data set presented earlier. The microseismic analysis will be discussed first. Results from the microseismic analysis will provide a basis for treatment modeling. 


\section{CHAPTER III}

\section{MICROSEISMIC ANALYSIS}

As discussed in the previous chapter, microseismic analysis is often used to estimate fracture geometry, orientation, and complexity. This chapter focuses on the microseismic analysis of the Horn River Shale play. Microseismic monitoring was conducted in 78 of the completion stages across 12 of the wells. The total number of microseismic events observed over 35 days was approximated at 15,000 based on a continuously updated velocity model. A combination of vertical and horizontal dual array monitoring sensors were used. The sensors were moved over the completion period in order to optimize the recording of the events.

Fracture stages were recorded on both sides of the pad with the majority of stages being recorded on the side of the pad which intersected the fault. Well $\mathrm{H}$ and Well Naught (herby referred to as well Z) were the only two wells in which all of the stages were recorded. Both of these wells are also on the side of the pad which was intersected by the fault. This chapter will begin with an overview of general trends observed in the microseismic data. Microseismic monitoring along the mapped fault will be investigated. We will then go over Wells $\mathrm{H}$ and $\mathrm{Z}$ for which complete data is available. After that, specific examples will be discussed in which unique behavior was observed while monitoring the treatment. Lastly, the chapter will close with a brief summary of findings from the microseismic analysis. 


\section{General Trends}

The hydraulic fracture treatments observed by microseismic monitoring showed a variety of behaviors. This could be due to the fact that the majority of treatments monitored by microseismic were those that occurred early on in the development of the pad. It is clear by examining the treatment reports that the operator was still in the process of optimizing the fracture treatments. For this reason, there is some variety in the treatments themselves fluid volume, proppant ratio, and number of perforation clusters per stage. Even after taking these issues into account, there were still interesting differences among the responses. These cases will be discussed later on in this chapter. Perhaps the most uniform behavior observed was fracture height. Figure 5 shows a cross section plot of all of the 78 stages monitored with microseismic. As illustrated in the Figure, almost all of the fractures were contained by the Ft Simpson and Keg River formations. A well log showing the formations was presented in the literature survey section as Figure 2. This is consistent with previous observations by Beaudoin et al. highlighted in the well log presented in Figure 2 of Chapter II. 


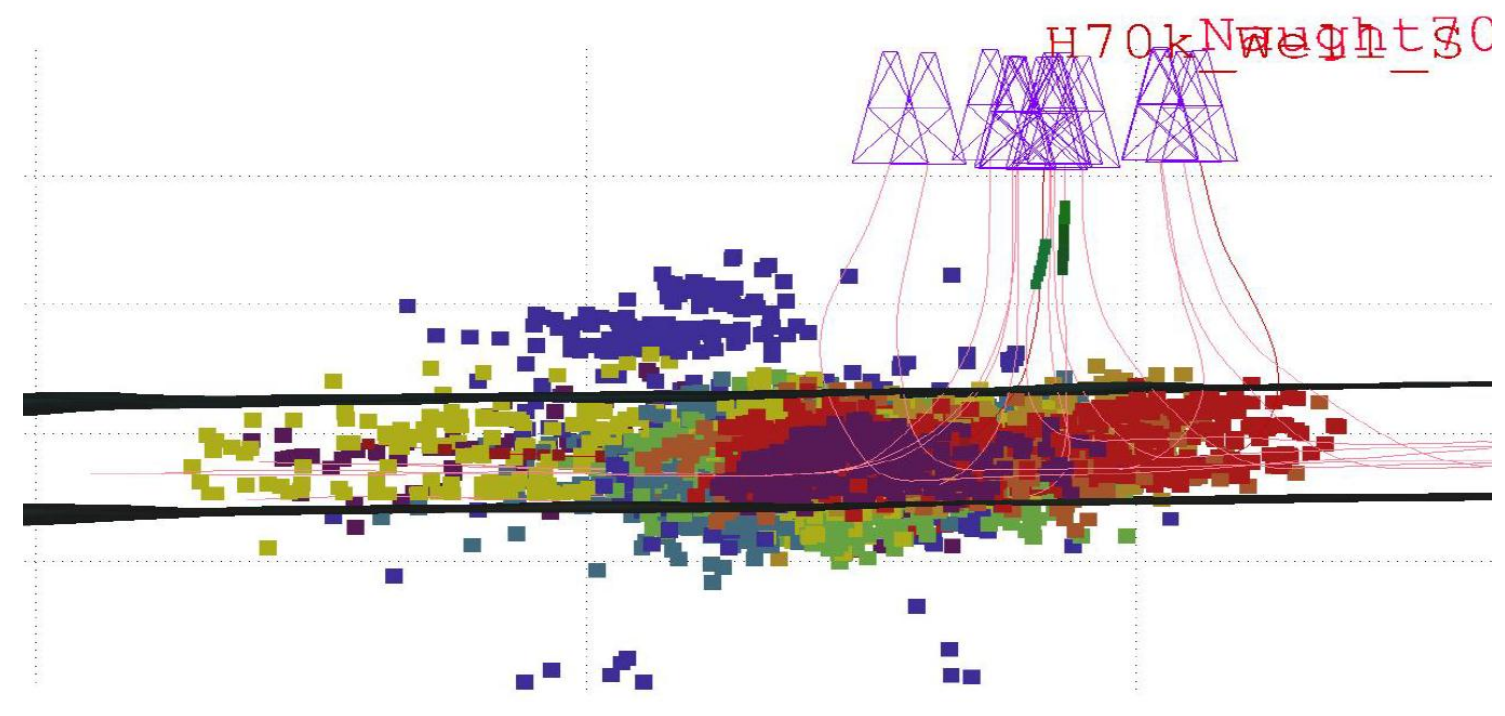

Figure 5 - Cross section view of all stages monitored by microseismic

Fracture height and half-length were estimated based on the cloud of observed microseismic events. The average fracture height was estimated at $825 \mathrm{ft}$. This is in accordance with the fracture barriers discussed in Figure 2. Reported fracture halflengths varied between $606 \mathrm{ft}$ and $3674 \mathrm{ft}$ with an average calculated to be $1526 \mathrm{ft}$. Figure 6 below is a plot of all of the fracture half lengths observed by microseismic monitoring. In order to appreciate the extent of the microseismic cloud, one must consider that the well spacing for this pad is about $880 \mathrm{ft}$. An average half-length of $1,526 \mathrm{ft}$ would imply that the fractures are extending on average beyond nearest neighbor wells and nearly reaching to the second wells from the treatment well.. This becomes even more apparent when pictures of the microseismic cloud are observed. 


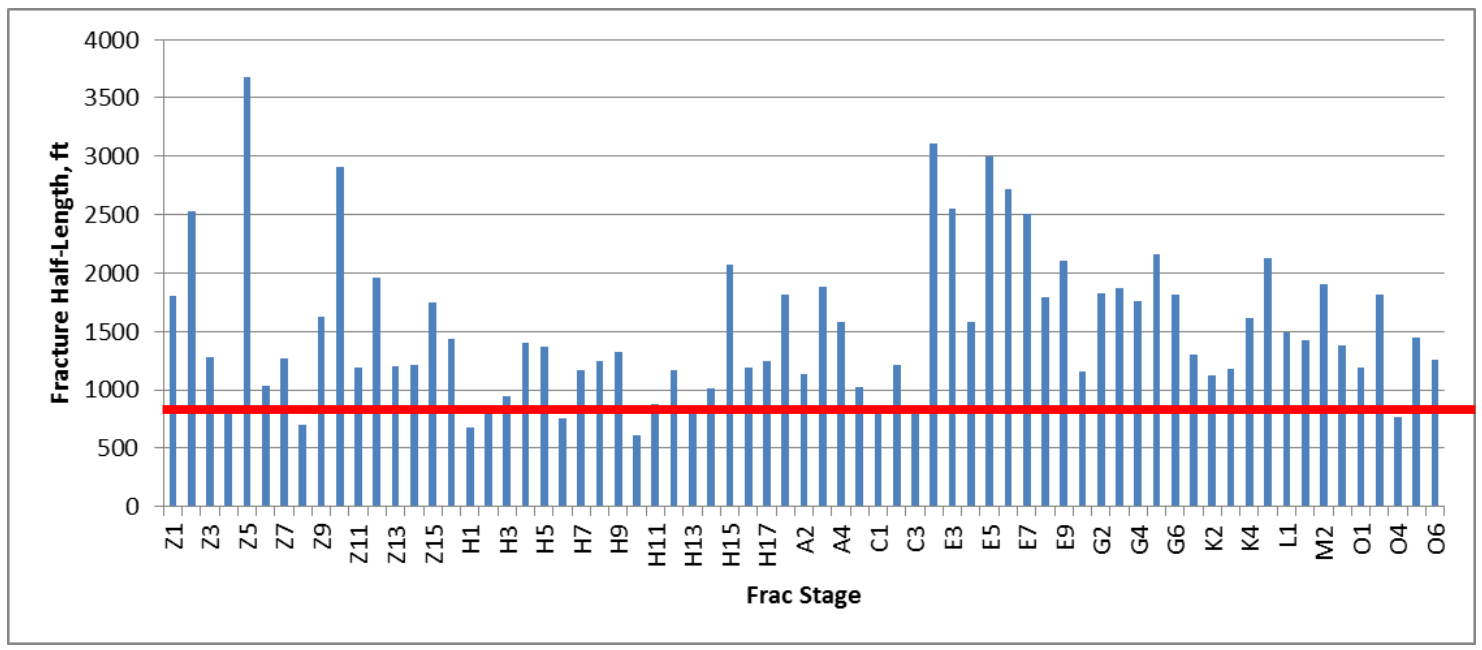

Figure 6 - Fracture half lengths observed by microseismic monitoring. The well spacing is $880 \mathrm{ft}$ represented by the red line

Figure 7 shows the first fracture stage from Well L. This is on the side of the pad which is not intersecting the fault. The fracture half-length observed in Well L was about 1,486 ft. This is slightly less than the average fracture half-length. As can be seen, the microseismic cloud extends over several wells. A similar extent of microseismic clouds is seen in other wells. When multiple stages are plotted together, there is a large amount of overlap observed. Another point which should be discussed is differentiating various fractures in the same stage. Typically it is assumed that one fracture exists for each perforation cluster. In the case of Well L, there were three perforation clusters which were separated by a distance of $82 \mathrm{ft}$ and $98 \mathrm{ft}$. In Figure 7, three fractures can be seen and they are highlighted by the blue lines. The perforation cluster is shown by the yellow dots. It can also be seen that the fractures are perpendicular to well. This was expected because the wells were drilled in direction of minimum horizontal stress. The fracture 
should open against the minimum horizontal stress implying transverse fractures. This is observed throughout the pad except for a few cases which will be discussed later on.

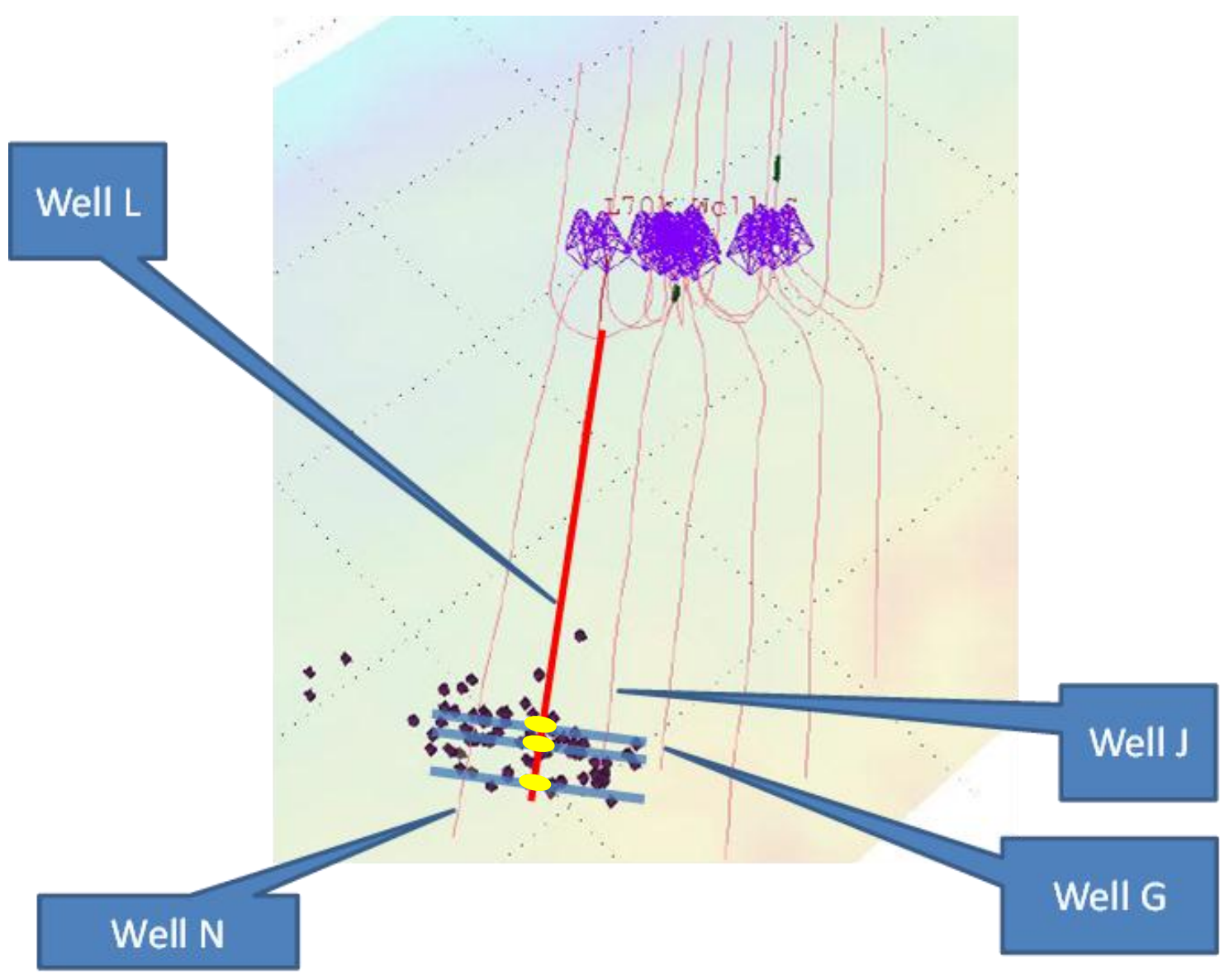

Figure 7 - Well L stage 1

In other wells, the microseismic cloud is denser than that observed in Figure 7. In those cases, it is much more difficult to differentiate between the fractures. This behavior is illustrated in fracture treatments of Well $\mathrm{H}$. 


\section{Well $\mathrm{H}$ and $\mathrm{Z}$}

Well $\mathrm{H}$ is one of two wells with complete microseismic data for each stage. It is also one of the first wells on the pad to be fractured. In general, the microseismic clouds in well $\mathrm{H}$ tend to be denser and more compact than those observed in Well $\mathrm{Z}$, the other well with complete microseismic data. The average half-length observed in well $\mathrm{H}$ was $1,103 \mathrm{ft}$.

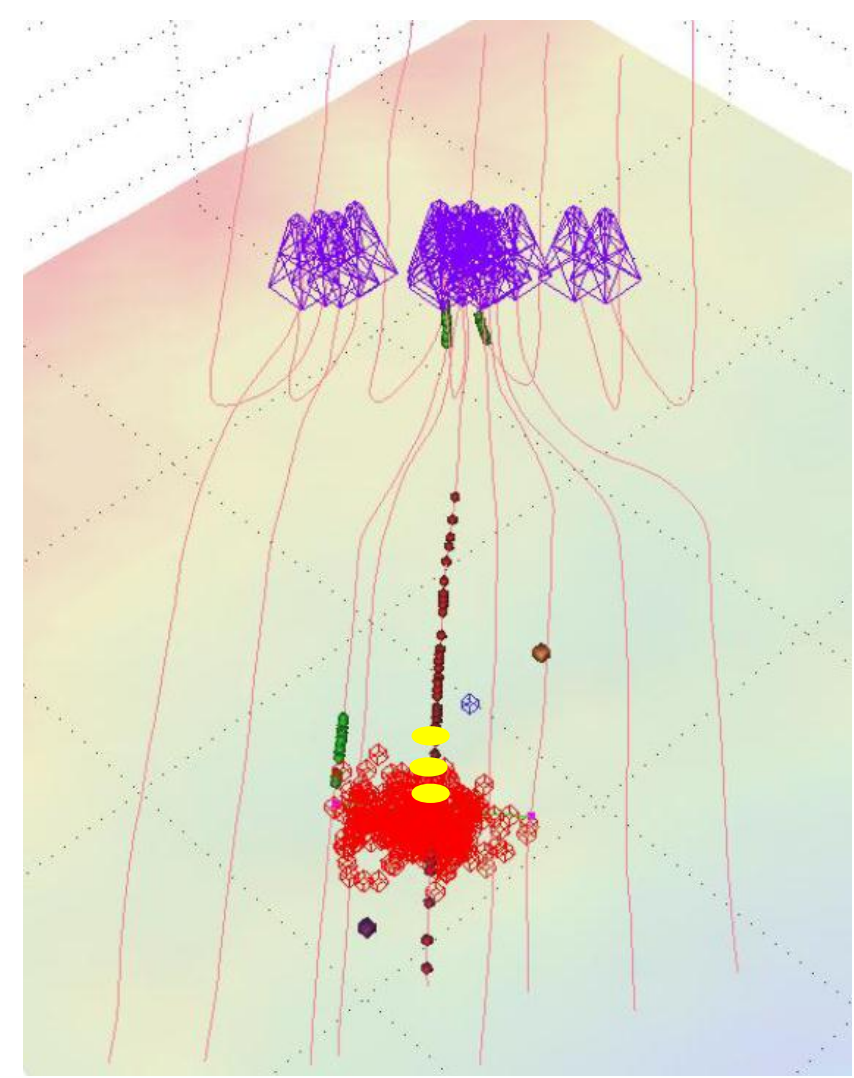

Figure 8 - Well H stage 7

A typical fracture stage from well $\mathrm{H}$ is shown in Figure 8. The perforation cluster is shown by the yellow dot. As seen in Well L, the fracture is again transverse to the well. In addition, the cloud is equal on both sides implying balanced growth. In this 
fracture stage, there were three perforation clusters. It is not possible however to identify three distinct fractures. This dense, interconnected cloud may suggest the creation of a fracture network also known as complex fracturing. However, it is possible that the density of the microseismic events is related to the locations of the geophone arrays, which are shown in each Figure as green points. The sensor array was much closer to the created fractures in this case, and, indeed, the event density appears greater nearest to the sensors.

Well $\mathrm{Z}$ was the second well in which all of the stages were monitored. All of the stages in well $\mathrm{Z}$ showed event clouds which were much larger than those observed in well $\mathrm{H}$. The average fracture half-length observed in well $\mathrm{Z}$ was $1,648 \mathrm{ft}$. Stage 5 of well $\mathrm{Z}$ had the largest estimated fracture half-length in the entire pad with a half-length

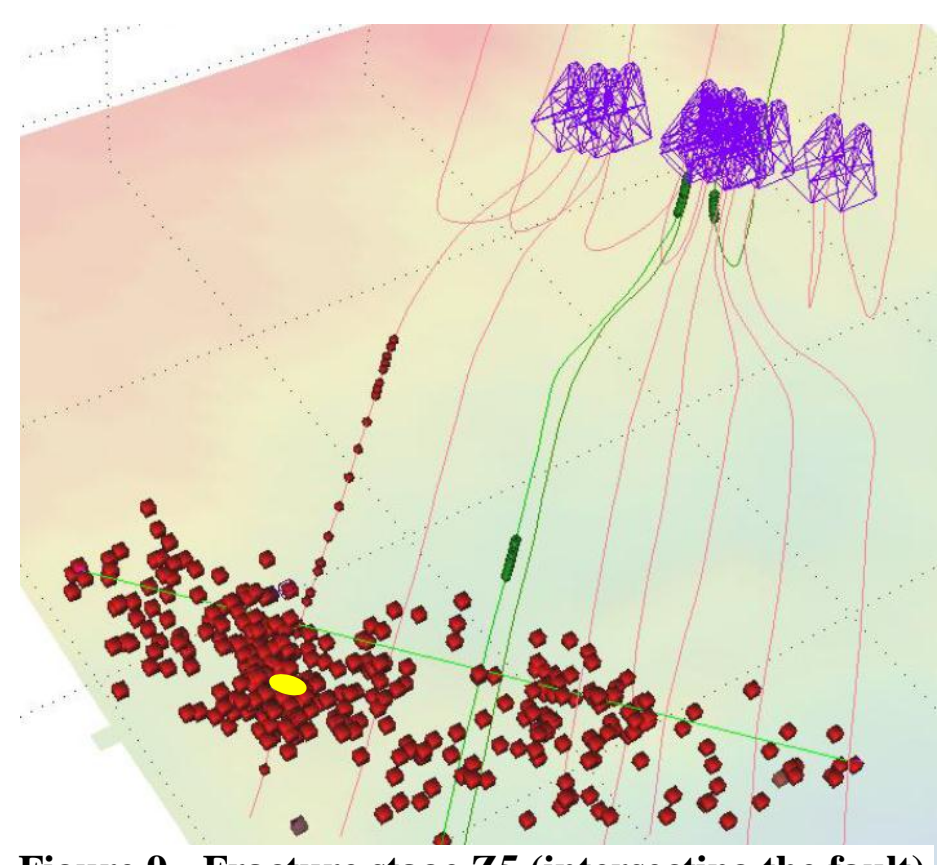

Figure 9 - Fracture stage $\mathrm{Z5}$ (intersecting the fault) 
of $3674 \mathrm{ft}$. Figure 9 shows the event cloud for Stage Z5. The perforation cluster is shown by the yellow dot.

The microsiesmic event cloud spans over the entire side of the pad. It should be noted that this is a stage which intersects the mapped fault. The fault may be causing the large cloud observed however this trend of is not observed consistently in other stages intersecting the fault. The cloud in Figure 9 also shows what appears to be asymmetrical growth in one direction. Again, this is most likely due to the location of the geophone arrays. The effect of microseismic sensor location has been discussed by many other authors. Other stages in the pad that were located closer to the sensors show much more balanced growth.

A very unusual stage observed in well $\mathrm{Z}$ was stage $\mathrm{Z} 2$. This was the only well in the entire pad with indications of substantial height growth passed the apparent fracture barriers. This well also showed a splitting trend towards the middle of the fracture treatment. Figure 10 shows two images of stage Z2. The image on the left is taken at early time and the image on the right is taken at later time. 

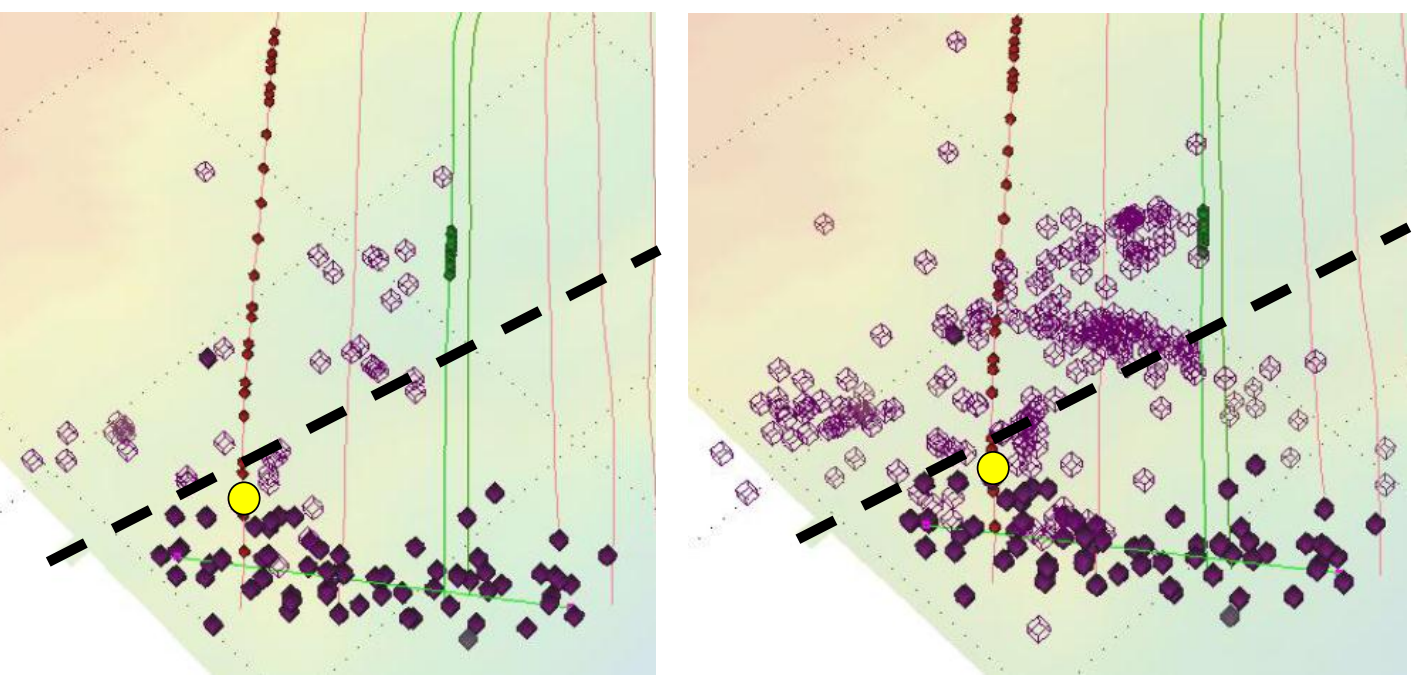

Figure 10 - Fracture Stage Z2 showing early time on the left and later time on the right. The light purple boxes are Stage $\mathrm{Z2}$ and the dark purple boxes are $\mathrm{Z1}$. The fault is represented by the black dashed line. The perforation cluster is shown by the yellow dot

From early on in the treatment, the distinct splitting trend can be seen. This

unusual behavior is contrary to the transverse fractures normally observed. Stage Z2 was one of the stages in close vicinity to the mapped fault. As Figure 10 shows, the splitting trend is parallel to the fault. Interaction with the fault could be a possible explanation for the divergent lateral growth as well as the unconfined height growth.

\section{Asymmetric Growth}

A few of the other stages also exhibited irregular fracture growth. Although none of the other stages showed height growth equivalent to that seen in Stage Z2, there were other types of unusual behavior observed. The term unusual or irregular is used because the fracture is not growing in the expected direction based on the stresses. 
One of the cases of irregular growth is the case of asymmetrical growth.

Asymmetric growth seen in Figure 9 was attributed to the sensor locations. This may be the case for well $\mathrm{Z}$ which was on the periphery of the pad. Some other stages however also exhibited asymmetric growth even though the sensors were located much more centrally than in the case of Well Z.

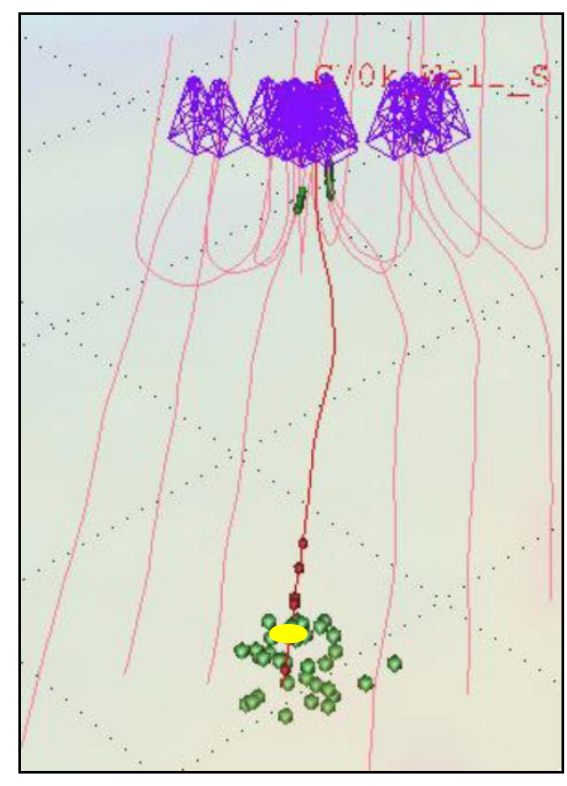

Early

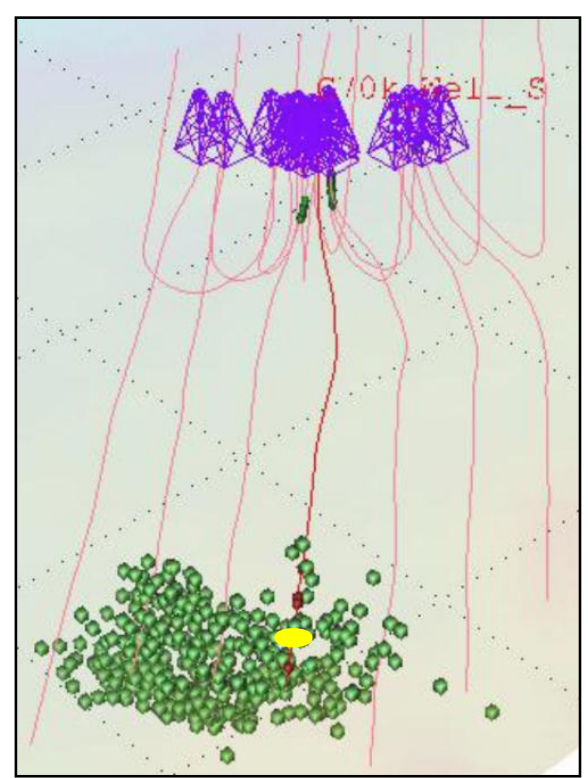

Late

\section{Figure 11 - Stage G3}

Well $\mathrm{G}$ is in the middle on the opposite side of the pad from the mapped fault. Stage G3 presented in Figure 11 shows two images of the treatment. The perforation cluster is shown by the yellow dot. The image on the left is taken early on in the treatment. The second image on the right is taken towards the end of the treatment. 
Initially there is balanced growth on both sides of the fractures. Later on however the fracture grows preferentially towards one side.

Another stage in which unusual growth is seen is stage 5 of well O. This well is located on the side of the pad with the fault however stage 5 is not in the vicinity of the fault. Figure 12 shows the final microseismic image of events for stage O5. The perforation cluster is shown by the yellow dot. As can be seen in Figure 11, the treatment diverts about $45^{\circ}$ from the expected path.

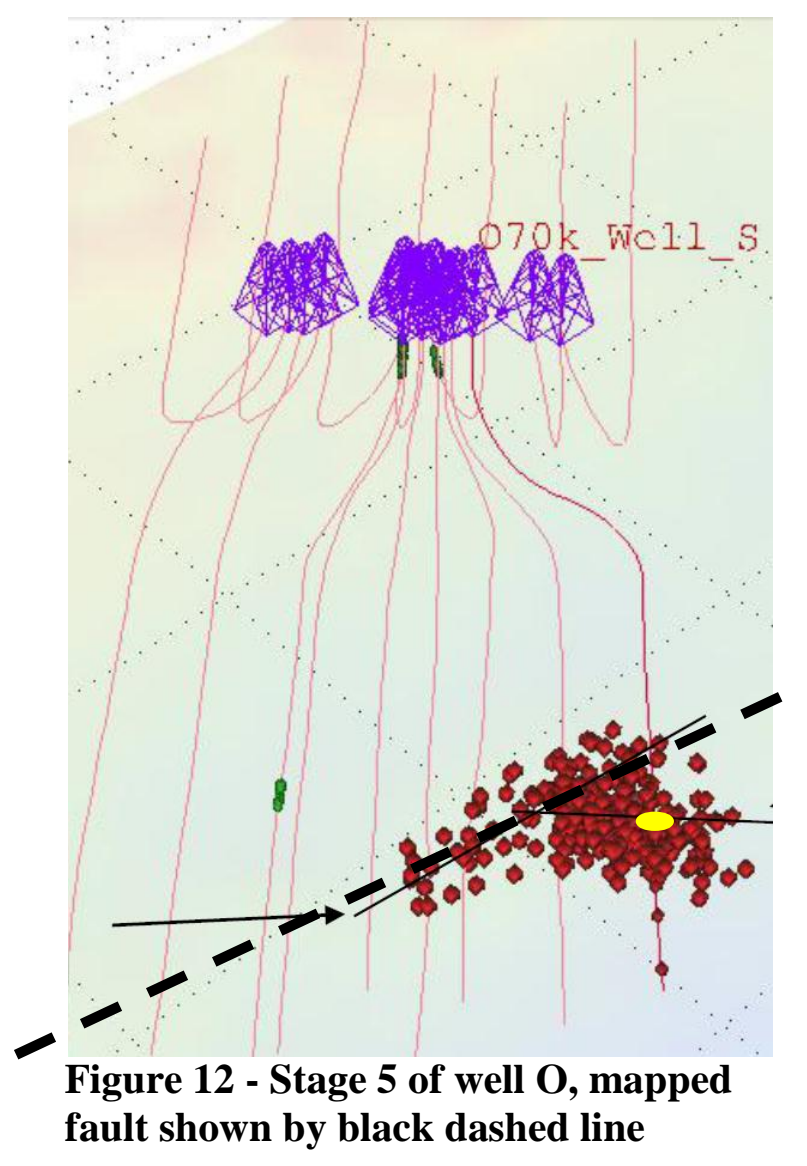


A basic principle in well stimulation is that the fluid will flow against the path of least resistance. This is why the fracture opens against the minimum stress. In the case of Stage O5, there must have been a conduit or flow path which caused the fracture to grow in the direction other than that dictated by the minimum horizontal stress. The mapped fault is shown in Figure 12 as a dashed-black line. The microseismic cloud of events at an angle to the main fracture clearly propagates along the mapped fault.

\section{Injected Volume vs. Half-length}

It was mentioned earlier in this study that there was a large variation of fracture half lengths throughout the pad. Intuition would lead to the assumption that fracture halflength is dependent on treatment volume. Large volumes should correspond to larger fracture half-lengths. Further investigation into this issue shows that this is not always the case.

Plots of fracture half-length based on microseismic versus injected fluid volume are shown in Figures 13-15. The injected volume was normalized by the number of perforation clusters present in a specific stage. Figure 13 is a plot of all of the treatments that were monitored by microseismic. Although there is scatter in the data, a positive correlation can be observed. Figures 14 and 15 show the injected volume vs. halflength for wells $\mathrm{Z}$ and $\mathrm{H}$ respectively. These plots show that there can be variation within the same well. A possible explanation for this variation could be fracture complexity. The larger fluid volumes may result in a more dense fracture network rather than longer half-length. 


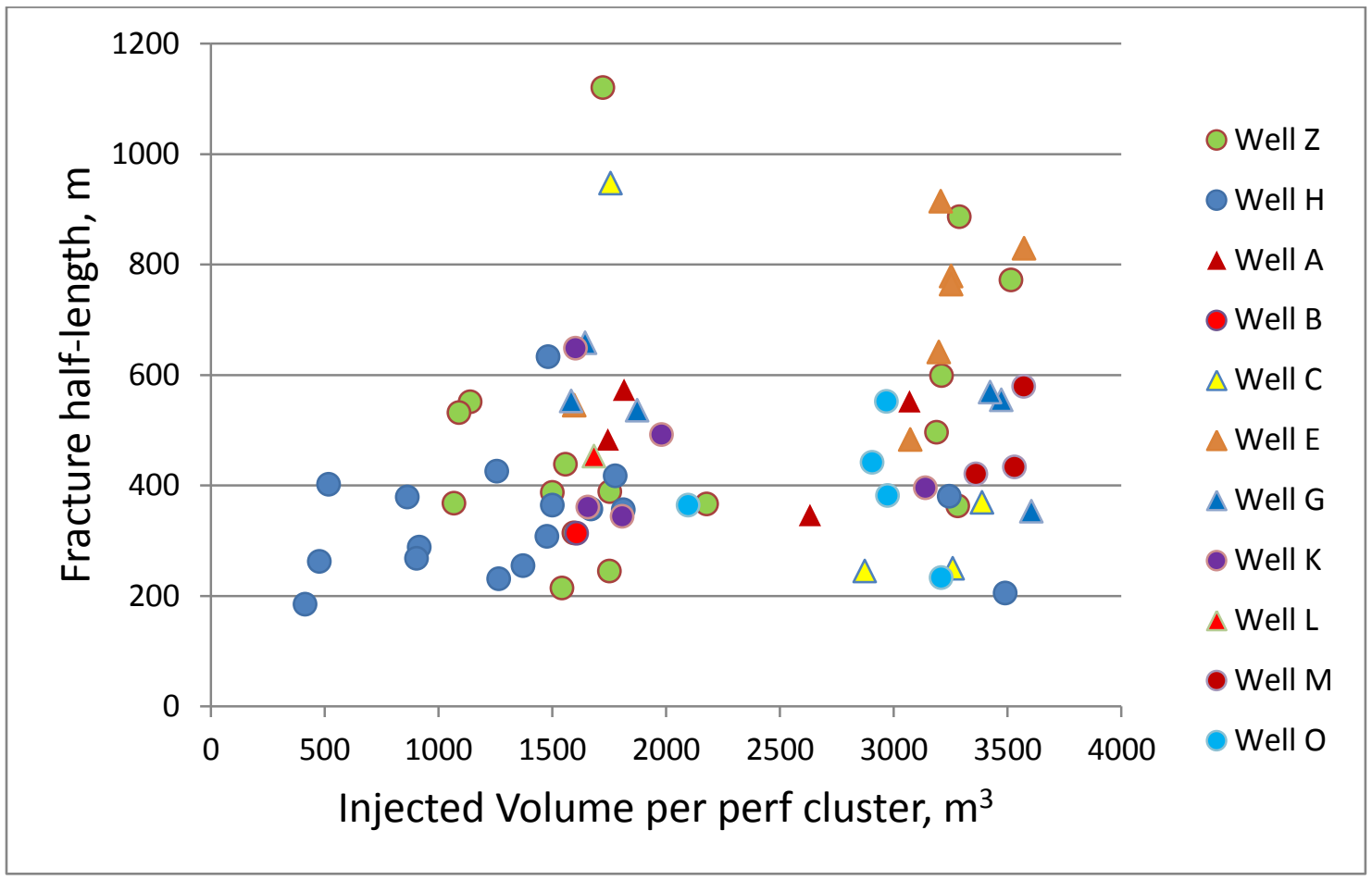

Figure 13 - Injected volume vs. $x_{f}$ for all wells. Wells intersected by the fault are circle dots and wells not intersected by the fault are triangles.

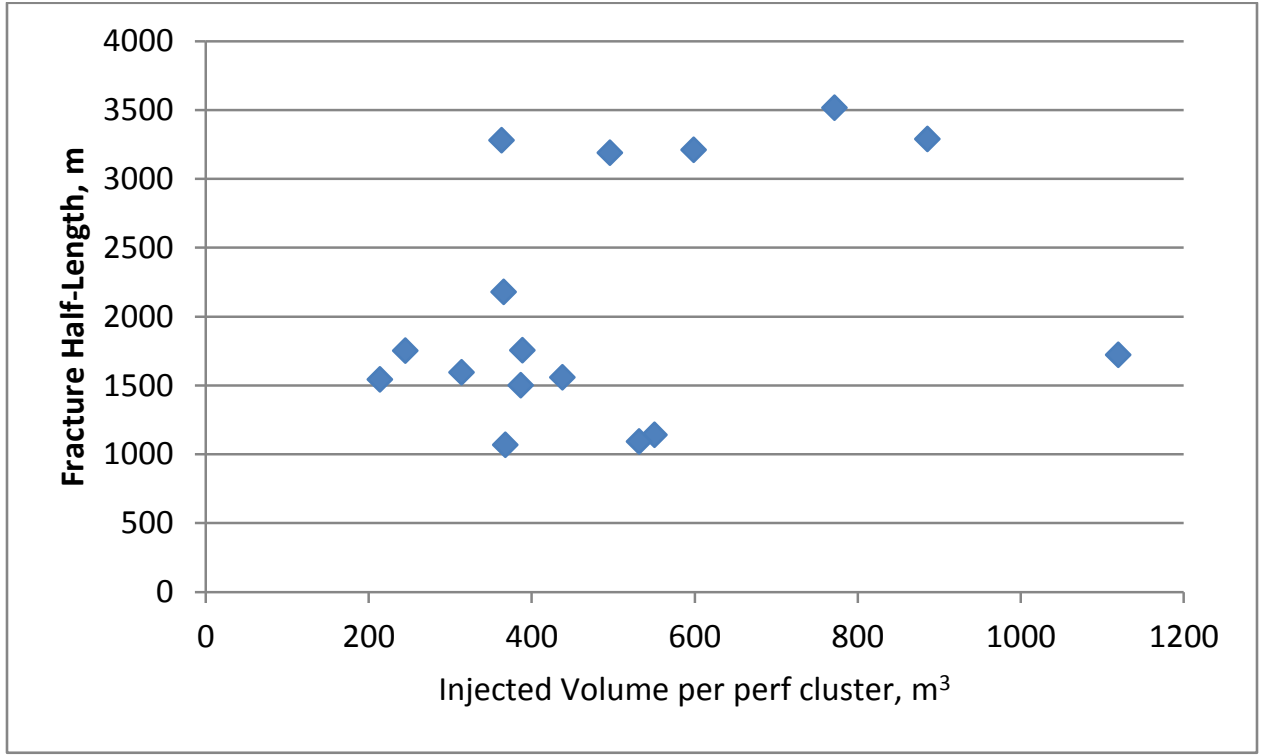

Figure 14 - Injected volume vs. half-length for well $\mathrm{Z}$ 


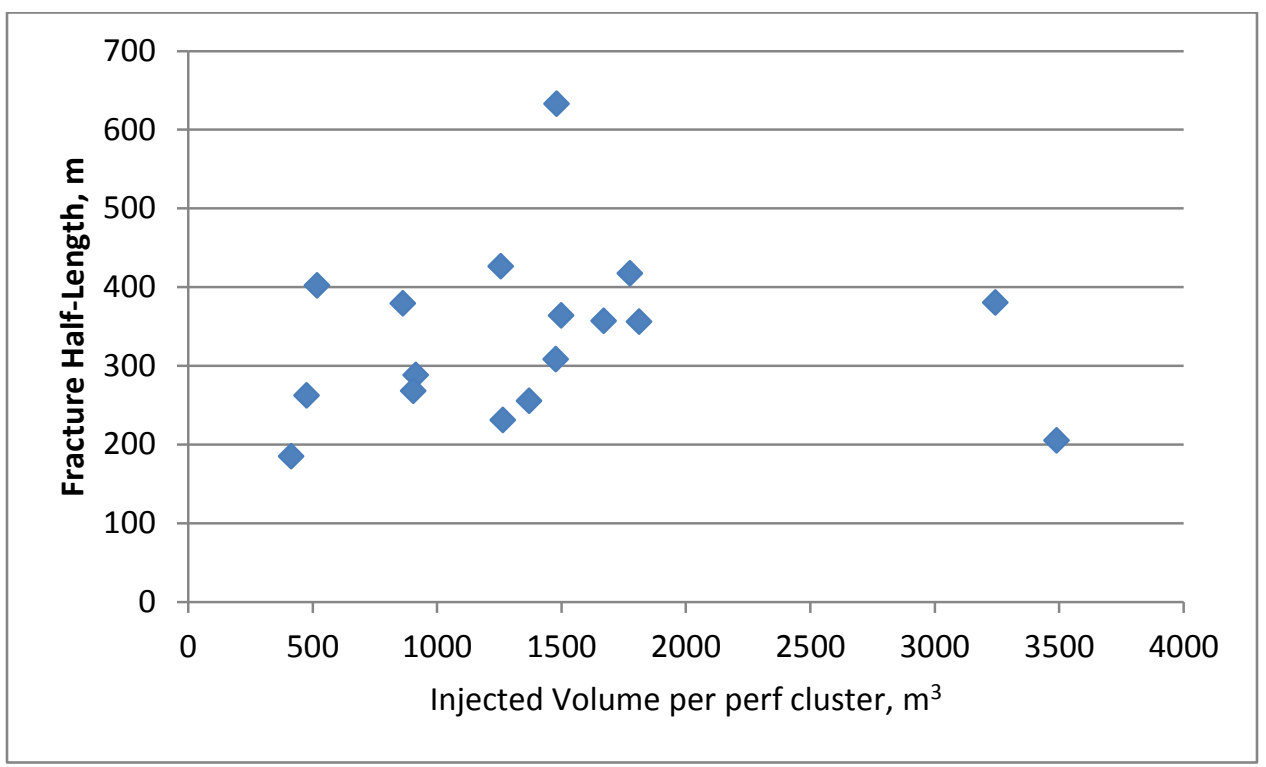

Figure 15 - Injected volume vs. half-length for well H

\section{Event Locations}

Another issue which was observed in some of the stages was that microseismic events were observed far from the well in the early stages of the treatment. Most of the microseismic data that was available for this study are still images taken towards the end of the treatment. One of the treatments that did contain snapshots at different times was stage E3 on the side of the pad opposite the fault. Figure 16 shows three images of the same fracture stage taken during early time, middle time, and late time of the fracture treatment. As one can see, microseismic hypocenters are seen far off from the well even in the early time image. The farthest hypocenters are over 4,000 ft from the treatment well. During personal communication, Dr. Mark Zoback from Stanford University, discussed the possibility of pressure events being observed far off from the actual 
fracture. It is suggested that these events may not be in direct connection to the main fracture and the

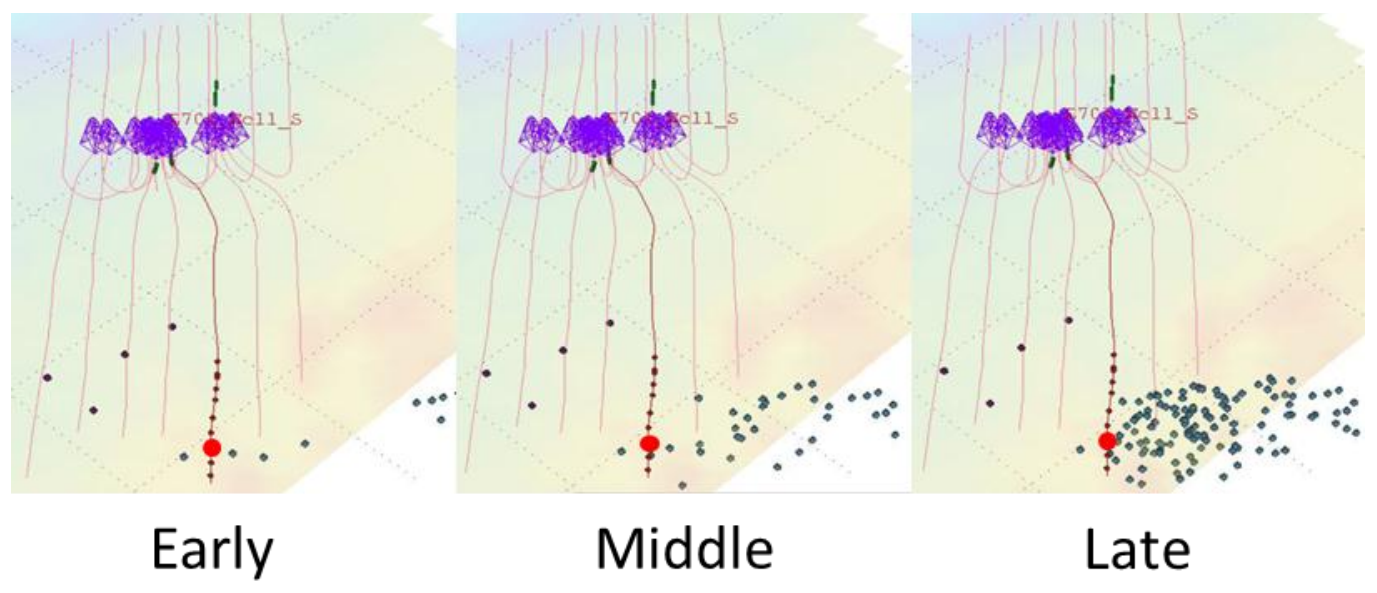

Figure 16 - Snapshots of stage E3 taken at various times during the treatment, perforation cluster is the red dot

fracturing fluid may not have reached these locations. The question arises as to how far off these events may be observed from the well. Fracture modeling must explain how injected volumes travel through the shale.

\section{Water Production}

As shown in all of the microseismic data presented in this chapter, the fracture half-length of the majority of stages was about double the distance between 2 adjacent wells. Another indication of large fracture half-lengths was water production anomalies which were observed in three wells, A, C, and E located on the northeast periphery of 
the pad. Figure 17 shows the northeast corner of the well pad. The well from the neighboring pad is circled in blue. It will be referred to as "neighbor well." The distance

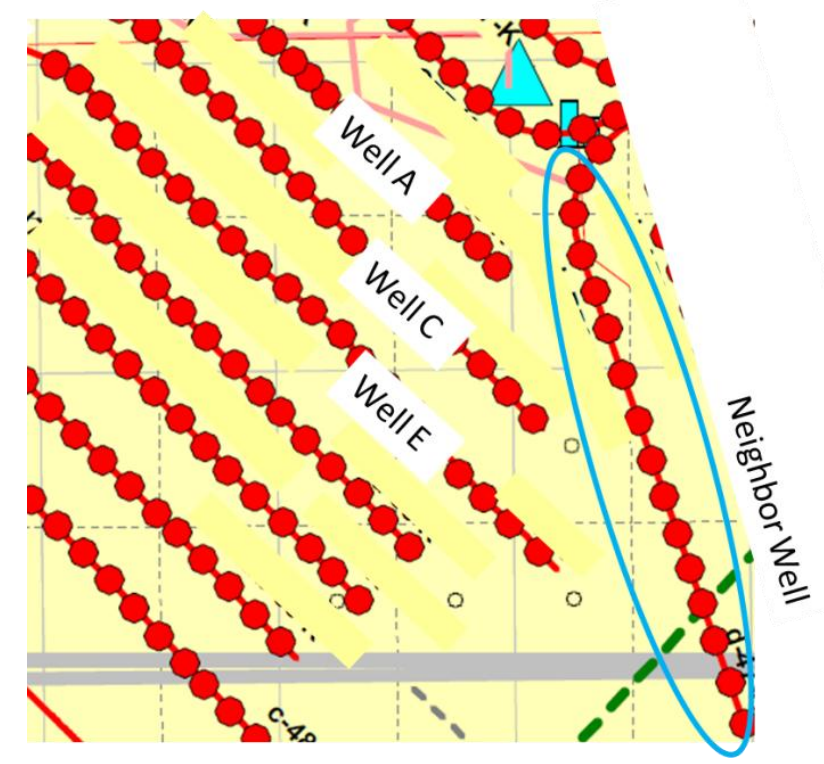

Figure 17 - Map showing neighbor well

from the neighbor well to well A is approximately $800 \mathrm{ft}$. The distance from the neighbor well to well $\mathrm{E}$ is approximately $2,000 \mathrm{ft}$. The water production plots for wells $\mathrm{A}, \mathrm{C}$, and $\mathrm{E}$ show an anomalous increase in water production. Figure 18 is a plot of cumulative water production for wells A, C, and E. All of the wells show an increase in water production at about 390 days. This corresponds to the time that the neighbor well was being fractured. This suggests a fracture half-length similar to that observed in the microseismic data. 


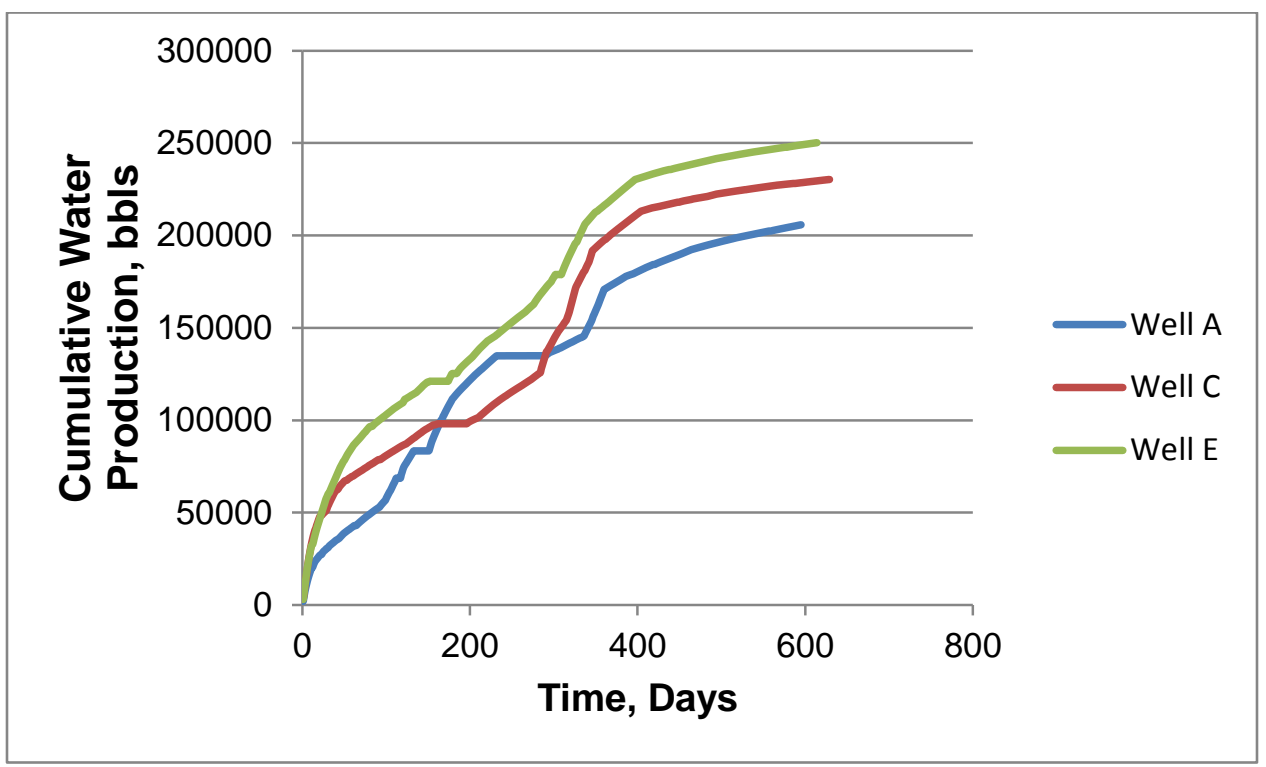

Figure 18 - Cumulative water production for wells A, C, and E

\section{Chapter Summary}

The following key findings can be deduced from microseismic analysis of the Horn River treatments:

- Fracture height growth is unrestricted until the Keg River and Ft. Simpson formations which are over $800 \mathrm{ft}$ apart

- The average fracture half-length observed from microseismic is $1,526 \mathrm{ft}$ which is almost double the distance between adjacent horizontal wells

- Most hydraulic fractures are perpendicular to the horizontal well

- The mapped fault appears to be causing irregular growth in some of the fracture stages 
- Variation in injected volume vs. created half-length could be explained by complex fracturing

- Anomalous water production from the neighboring well pad suggest fracture half-lengths similar to those observed by microseismic analysis

The next chapter uses insights from the microseismic interpretation to calibrate models for the hydraulic fracture treatments. 


\section{CHAPTER IV}

\section{TREATMENT MODELING}

Microseismic analysis gives estimates of created fracture geometry however it cannot be used to estimate propped fracture geometry. In order to estimate both created and propped fracture geometry, treatment modeling must be conducted. This chapter will discuss the process of net pressure analysis and treatment modeling. The FracproPT simulator was used to mdel the treatments. More background information about FracproPT was provided in Chapter II.

\section{Material Balance}

One of the key concerns in modeling the hydraulic fracture treatment is to maintain material balance. Ehlig-Economides et al. (2012) showed that the permeability of the Horn River shale is in the nano-darcy range. Other authors have presented similar estimates of shale permeability. This extremely low permeability results in very low leak-off into the matrix during the fracture treatment. In other words, the fluid efficiency of the fracturing fluid is very high. Fluid efficiency is defined as the volume of the created fracture divided by the cumulative volume injected during the treatment. The fluid efficiency is usually estimated during a fracture calibration test (FCT) conducted prior to the main fracture treatment. Another study of the Horn River data set focuses on the FCT analysis for these wells. It is estimated that the fluid efficiency for the Horn River treatments is slightly above $90 \%$. Maintaining material balance will limit the number of erroneous matches that could be obtained. 


\section{Friction}

When dealing with surface recorded pressure data, it is essential to remove all effects of friction on the observed net pressure. Errors in friction modeling will generally result in step changes in observed net pressure at abrupt injection rate changes. If the perforation and near-wellbore friction are modeled correctly (meaning removed), observed net pressure will be smooth over periods of abrupt flow rate changes.

The instantaneous shut-in pressure (ISIP) can be used to estimate the correct frictional coefficients. The ISIP is the pressure observed immediately after the pumps are shut-in. If the pressure data is continued to be acquired after the shut-in, a pressure falloff curve is sometimes observed. The sharp drop in surface treating pressure observed at an ISIP is due to the loss of the combination of perforation, near-wellbore, and wellbore friction. The abrupt change in downhole pressure that is observed at an ISIP represents the sum of perforation and near-wellbore friction. If the friction is modeled correctly, there will be no sharp drop of pressure when the pumps are shut-in.

This is the technique that was used in order to estimate the correct frictional coefficients for the Horn River wells. Due to the fact that the treatments were not all uniform, the frictional pressure drop varied slightly for each stage that was modeled. Perforation size and density were known to have a substantial effect on friction. One of the more common perforation designs in the Horn River wells is shown in Figure 19. According to the field reports, 3-3/8" perforation guns with 25 gram charges were used. This results in a perforation diameter of about $0.45 "$ in 5.5 " casing. The density of perforations used was on average, 6 shots per foot. 

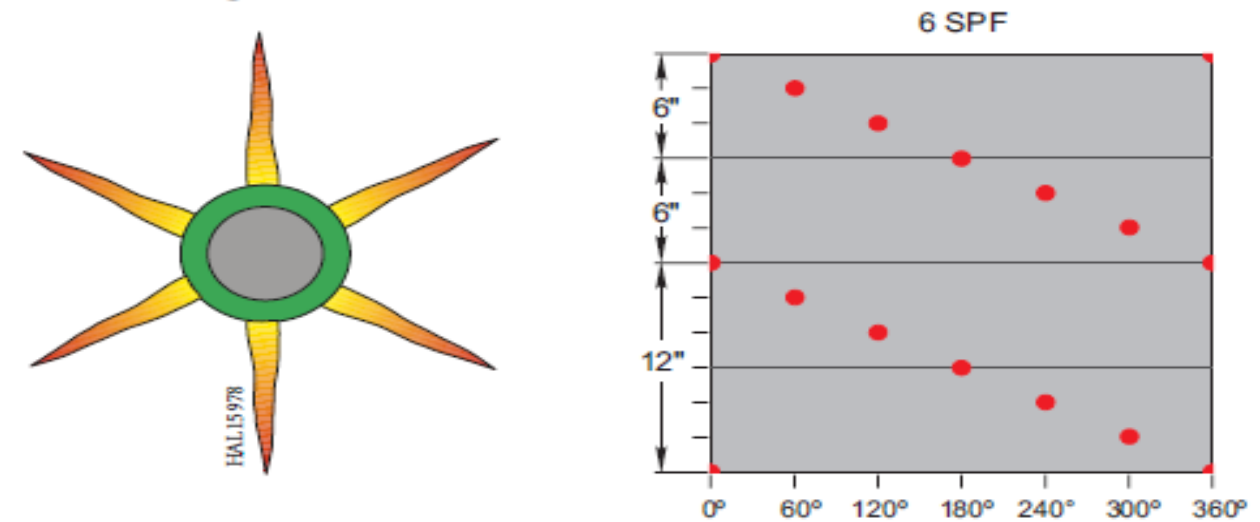

Figure 19 - Perforation design for Horn River wells

\section{Model Inputs}

A well log from another Horn River development was shown in the literature survey section of the report. Much of the lithology inputs used in the simulator were provided by the operator. A lithology profile from one of the stages is presented in Figure 20.

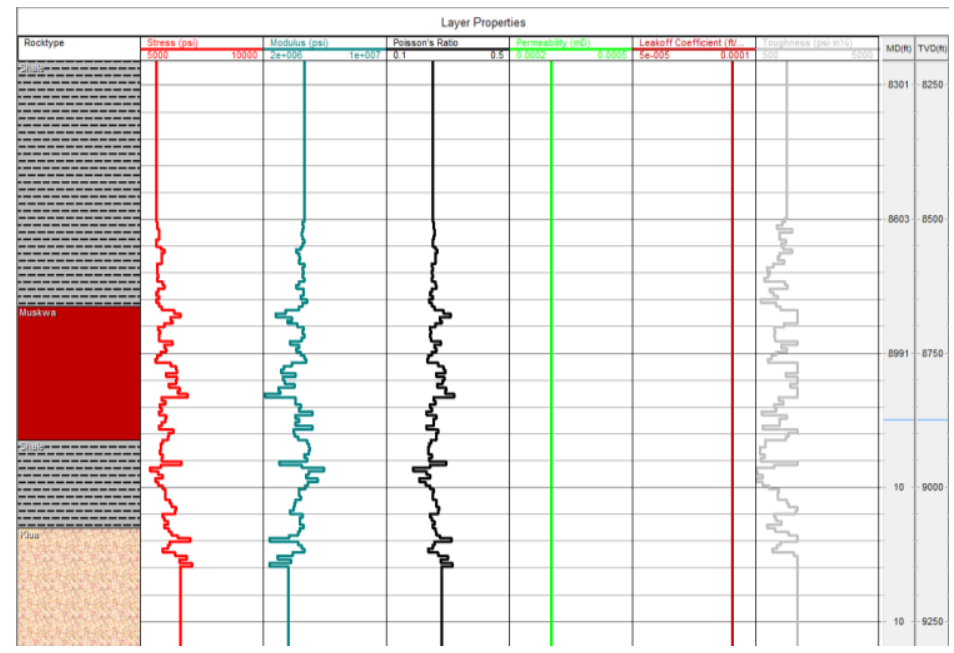

Figure 20- Lithology profile used in FracproPT 
Detailed model inputs are presented Appendix A. Tables 2-4 show the values that were used for the multiple fractures feature in FracproPT. The numerical values input for this feature do not correspond to the number of fractures created. Table 5 presents the Young's modulus, stress gradient, Poission's ratio, and fracture toughness. These values were provided by the operator and they are similar that which was presented in other studies of the Horn River Shale. The data presented in Table 5 is from well L however similar lithology input was used throughout the pad. The Young's modulus observed in Horn River ranged from $1.6 \times 10^{6}$ psi to $9.5 \times 10^{6}$ psi. The Poission's ratio was around 0.25. A constant leak-off rate of $6.8 \mathrm{E}-05 \mathrm{ft} / \mathrm{min}^{0.5}$ was assumed. The red curve on the left side is the stress. There are no major stress contrasts in the zones of interest. The stress in the formation below the payzone was higher than what was observed above the payzone. This caused the fractures to preferentially grow upwards. Due to this fact, the
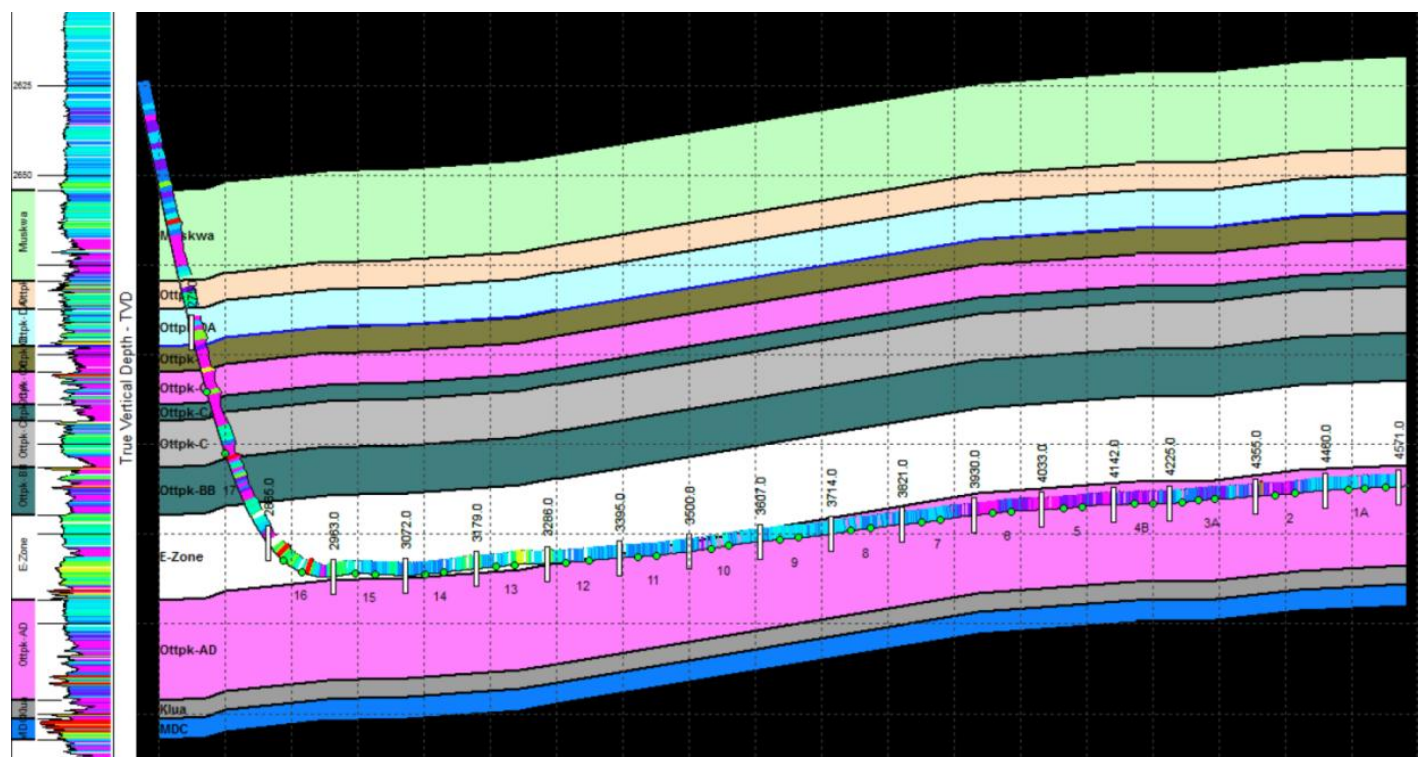

Figure 21 - Well L cross-section 
majority of wells were drilled towards the bottom of the Otterpark formation. The fractures extended upwards covering the Otterpark and Muskwa shales. A crosssectional image of the well trajectory is shown in Figure 21. The green dots are perforation clusters and the white bars are the divisions for each stage. The fracture treatments for these wells started with the toe of the horizontal well. Bridge plugs are placed after each stage to isolate the other intervals. After completing all of the fracture stages, the bridge plugs are drilled out.

The cross section view in Figure 21 also shows the perforation clusters for each stage. There was an average of about 2 perforation clusters per stage. For fracture modeling purposes, one fracture is modeled for every perforation cluster. This assumption is based on the production logs that were run in some of the wells. Figure 22 shows the production log of well $\mathrm{C}$. This production log confirms that a fracture has been created for each perforation cluster. 


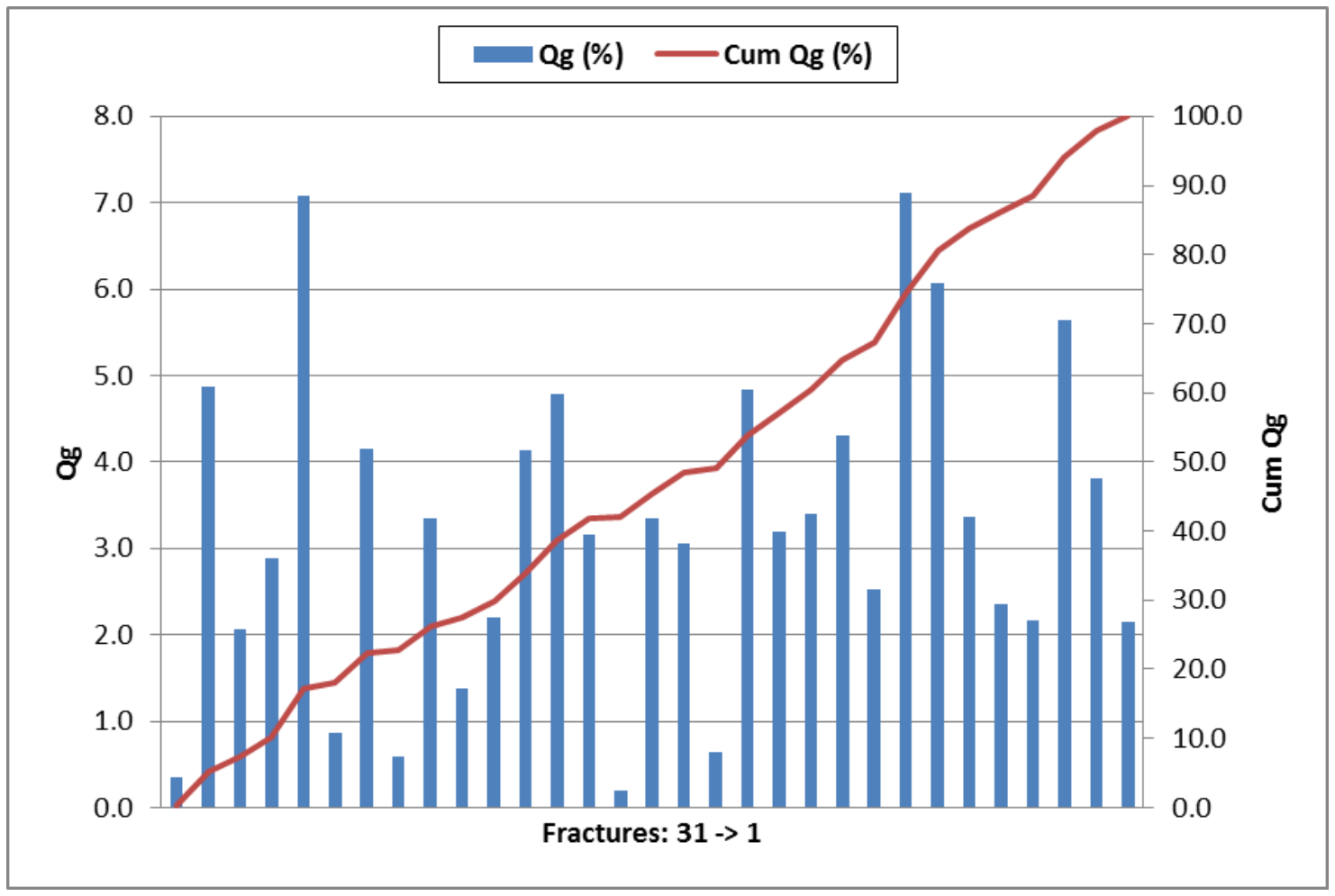

Figure 22 - Production log for well C

\section{General Trends}

The net pressures of numerous treatments were examined in order to understand the general behavior of the treatments. All of the treatments in Well J and Well D were modeled. The field reports for each treatment were examined in order to provide accurate information about the treatment. The frictional pressure loss had to be modeled individually for each stage in order to ensure the correct values for net pressure.

Combined plots of the observed net pressures for Wells $\mathrm{J}$ and D are presented in Figures 23 and 24 respectively. Each of these wells were taken from opposite sides of the pad. 
Well D was on the side of the pad which intersected the fault. The ISIP values have been clearly marked with colored dots at the end of the treatment.

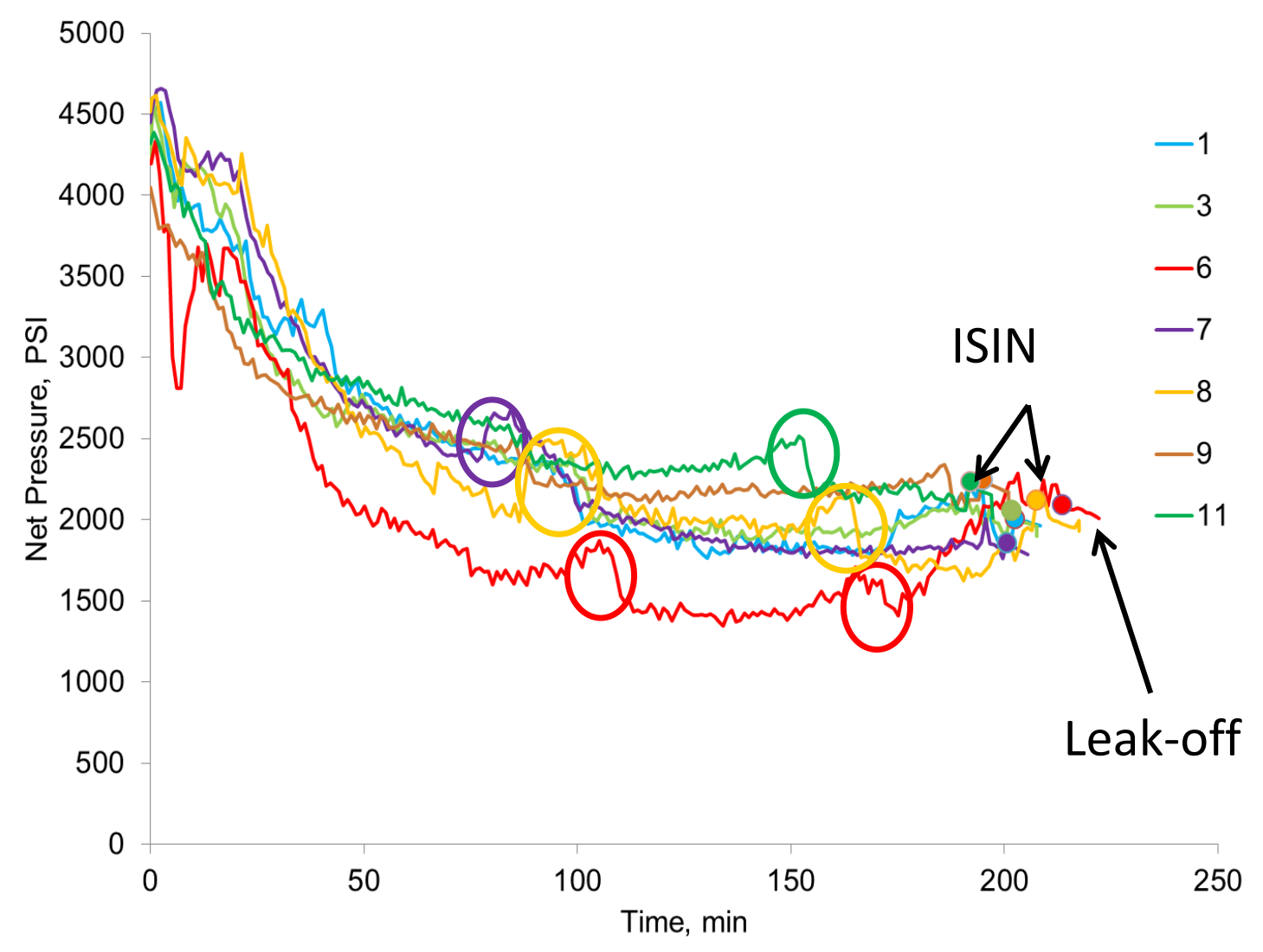

Figure 23 - Observed net pressure for well J

In order to create a comparative plot, the time zero for all treatments was shifted to the breakthrough pressure. Short periods of increased pressure were consistently observed throughout Well J. These "bumps" are circled on Figure 23. The increases in pressure were up to $500 \mathrm{psi}$. The consistent timing of these events in each treatment 
stage suggests that there could be a geological explanation for these events. The fracture may encounter a layer with different rock properties. The increase in pressure is observed until this layer is crossed. Unfortunately we cannot confirm this hypothesis with microseismic because Well $\mathbf{J}$ was not monitored by microseismic.

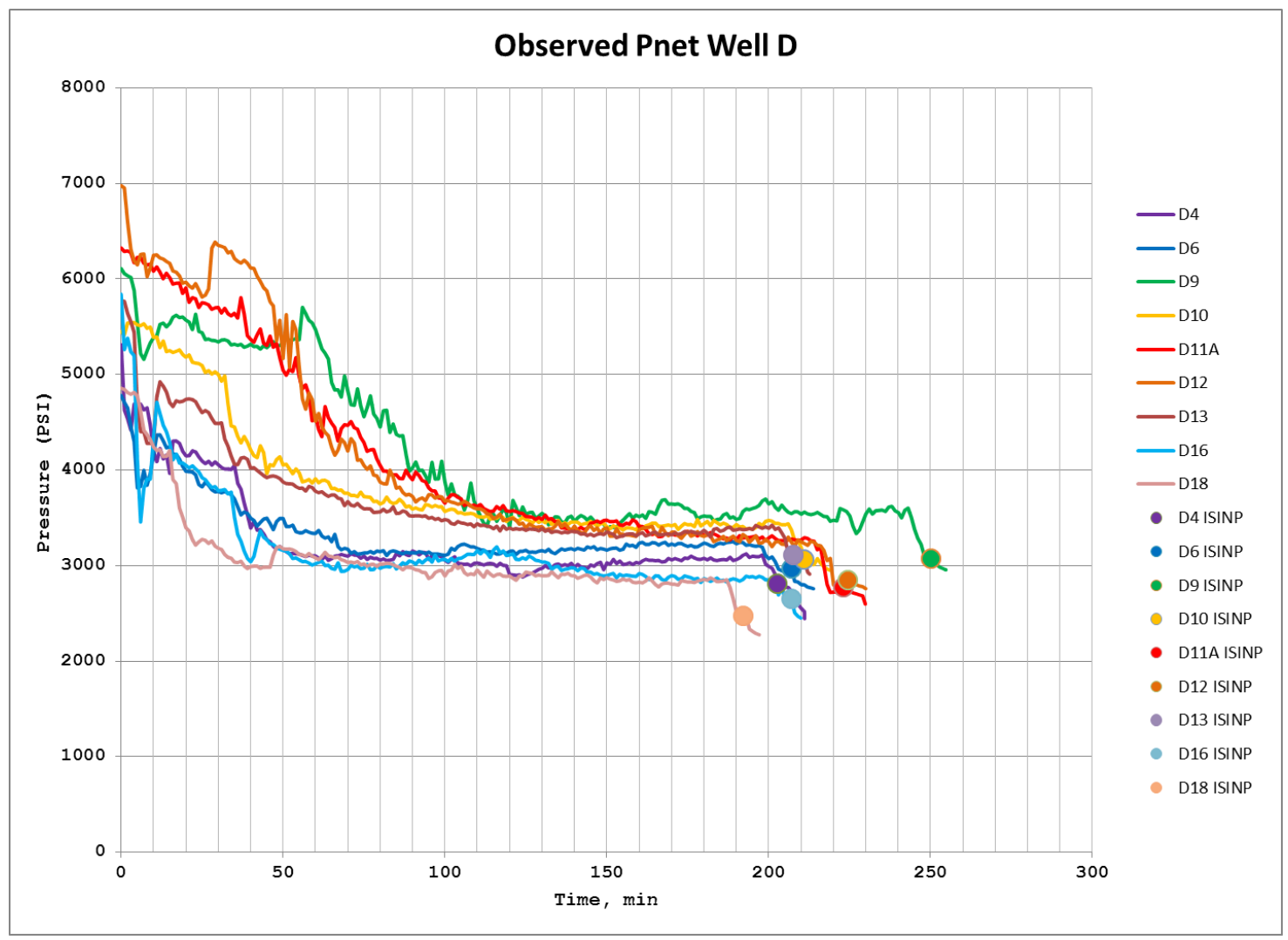

Figure 24 - Observed net pressures for well D

The Nolte-Smith analysis of net pressure (Economides and Martin, 2008) described in Chapter II requires plotting the pressures on a log-log scale. Figures 25 and 26 are the log-log plots of Wells $\mathrm{J}$ and D respectively. Although log-log scale is useful 
for understanding the overall trend, the future plots in this report will not use log-log scale. The reason for this is that certain behaviors, such as the bumps of pressure observed in well J, may not clearly be visible on the log-log scale. These behaviors may be masked even if the pressure change is over 500 psi as seen in well J. These wells show a mainly downward trend described in Chapter II as characteristic of radial fracture growth .

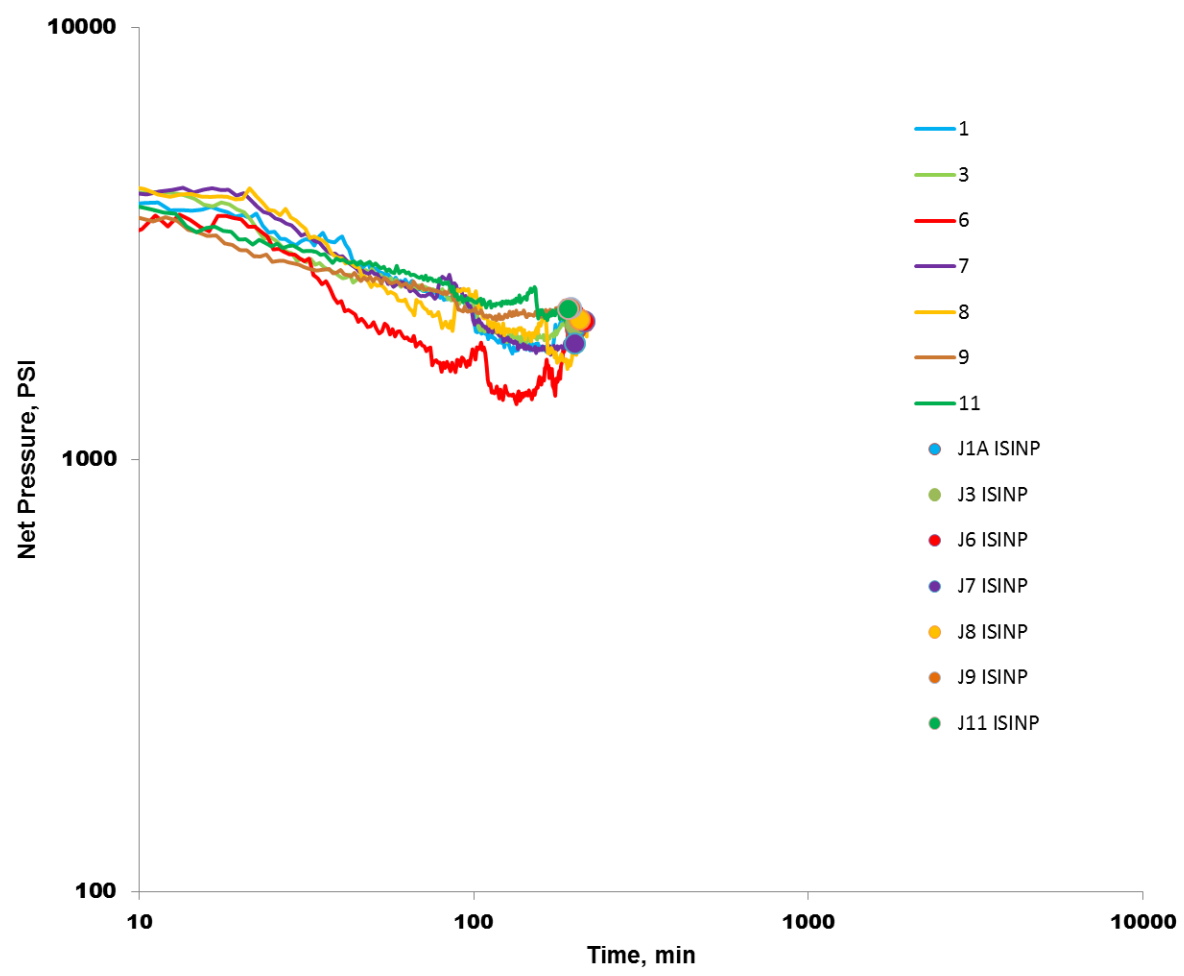

Figure 25 - Log-log plot of well J net pressures 


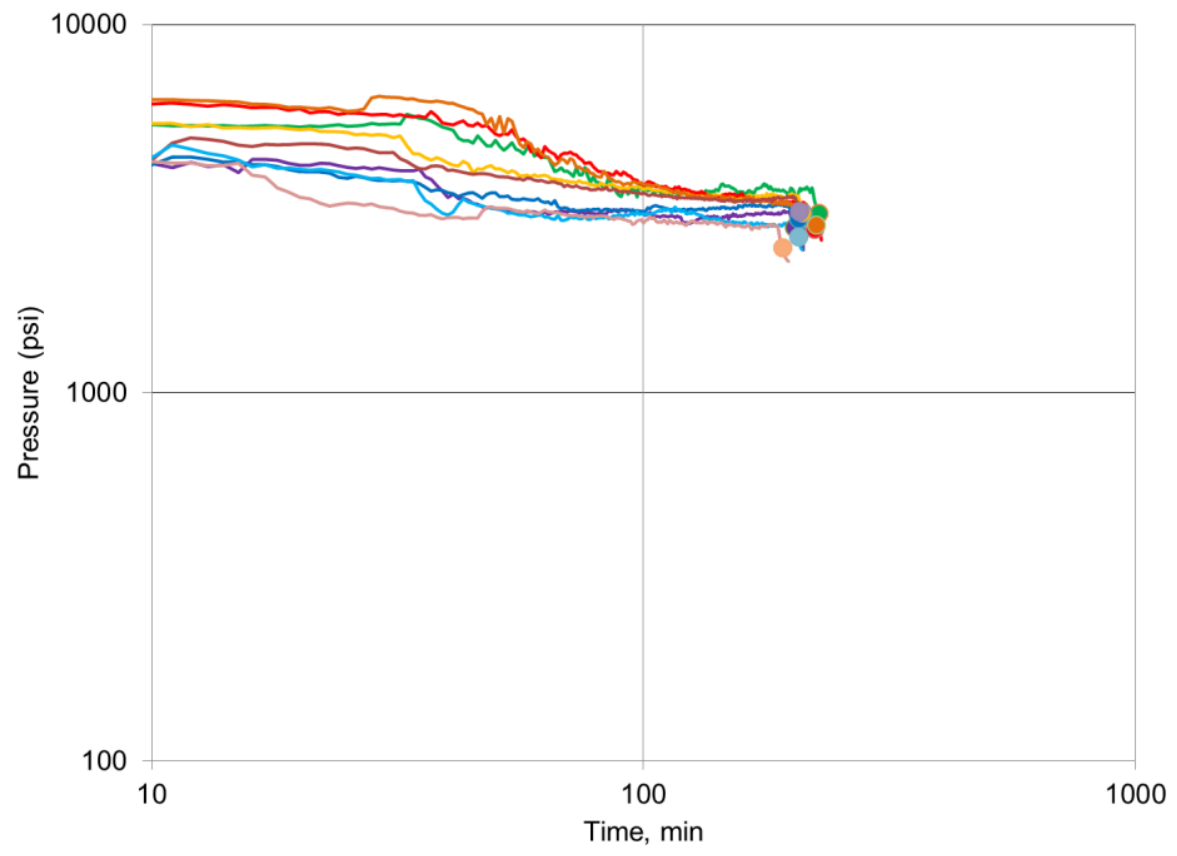

Figure 26 - Log-log plot of well D net pressures

When the pressures are in log-log scale, the slopes can be used to identify fracturing behavior. As Nolte and Smith mentioned, the negative slope observed in both of these plots implies significant height growth. This was mentioned as mode IV fracturing in Chapter II. This is an underlying trend that was observed throughout the pad.

Another finding from these net pressure plots is that the ISIPs observed were fairly consistent. Many authors, including Hurd and Zoback (2012) have cited that ISIP values vary 600 psi over the different stages in a particular well and suggested that early treatments can affect the stress regime in the surrounding rocks which would impact the 
ISIP. However, their ISIP estimates were based on surface pressures. Figure 27 and 28 clearly show that the ISIP variation is not monotonic.

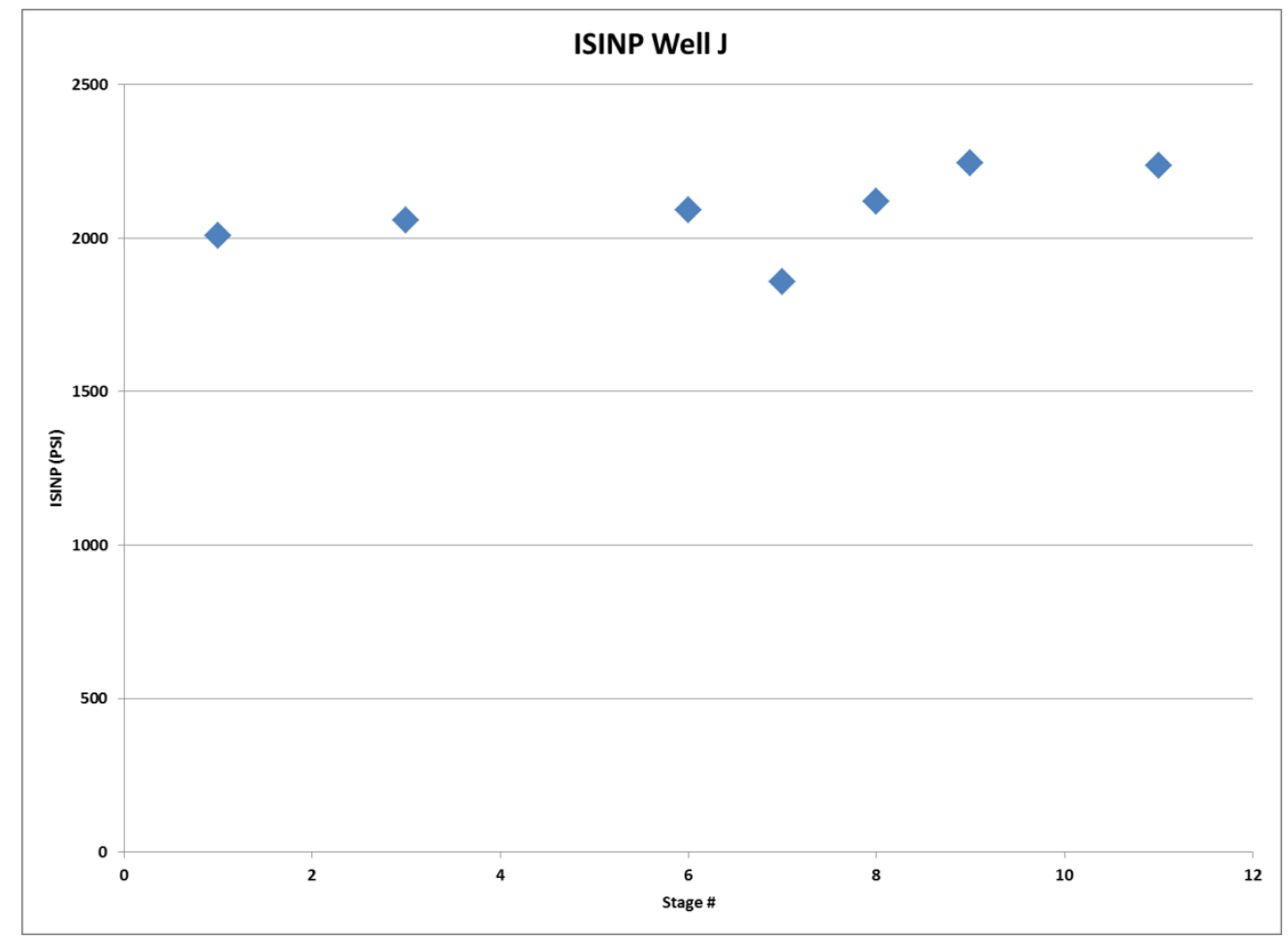

Figure 27 - ISIP values for well J 


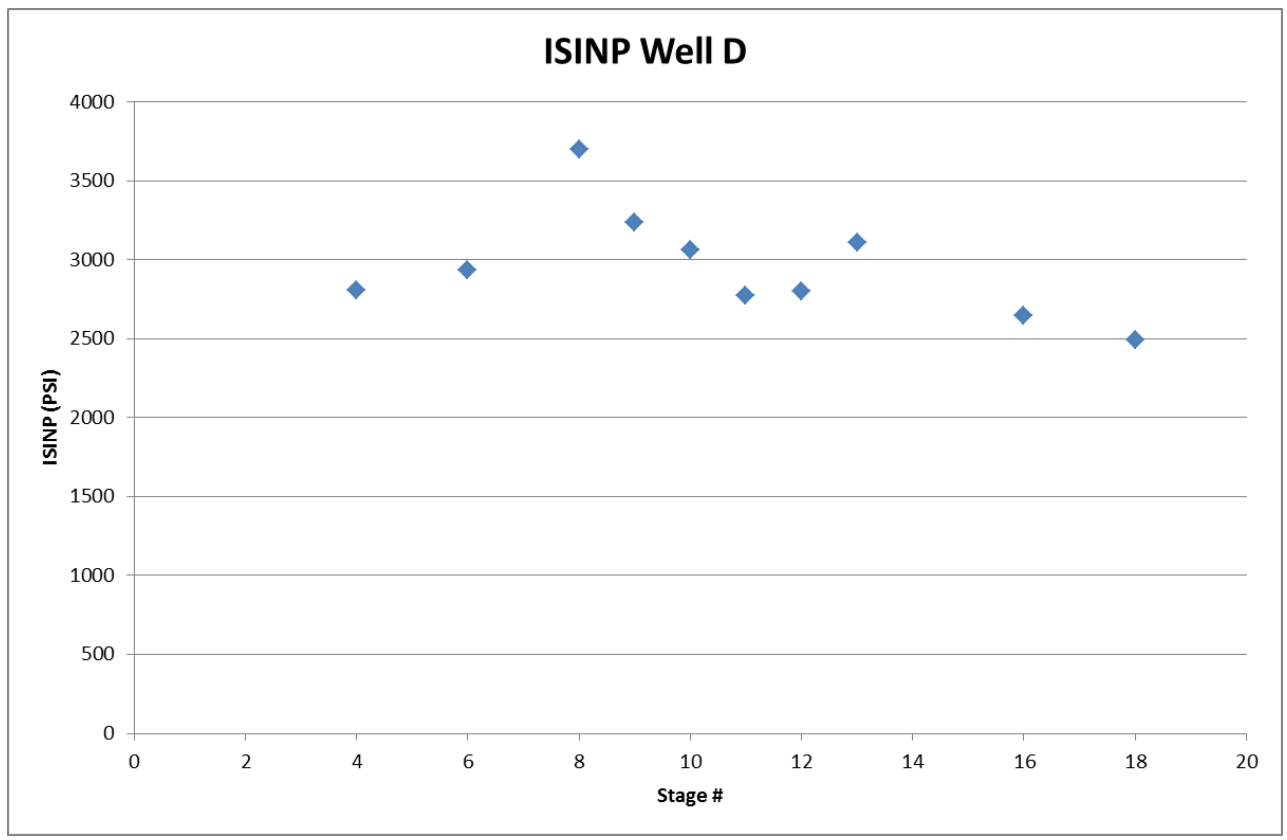

\section{Figure 28 - ISIP values for well D}

\section{Net Pressure Matching}

The microseismic events suggest fractures with large but contained height and extensive lateral extent. Direct evidence that fracturing fluid reaches distances on the order of that seen in microseismic clouds was seen as excess water production in the 3 outermost wells on the northeast side of the pad during fracturing of a well in the next pad (Ehlig-Economides et al (2012). Therefore, it is reasonable to target microseismicbased fracture extent in matching treatment pressure behavior.

The microseismic image of stage L1 was presented in Figure 7. The perforation clusters for stage L1 are presented in Figure 29. In general it is assumed that one fracture is created per perforation cluster. 


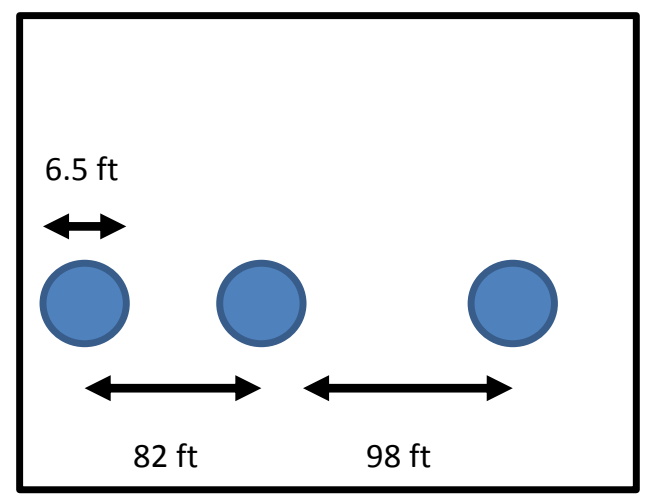

Figure 29 - Perforation clusters for stage $L 1$

The net pressure match obtained for stage L1 is presented in Figure 30. The blue curve is the observed net pressure and the red curve is the model net pressure.

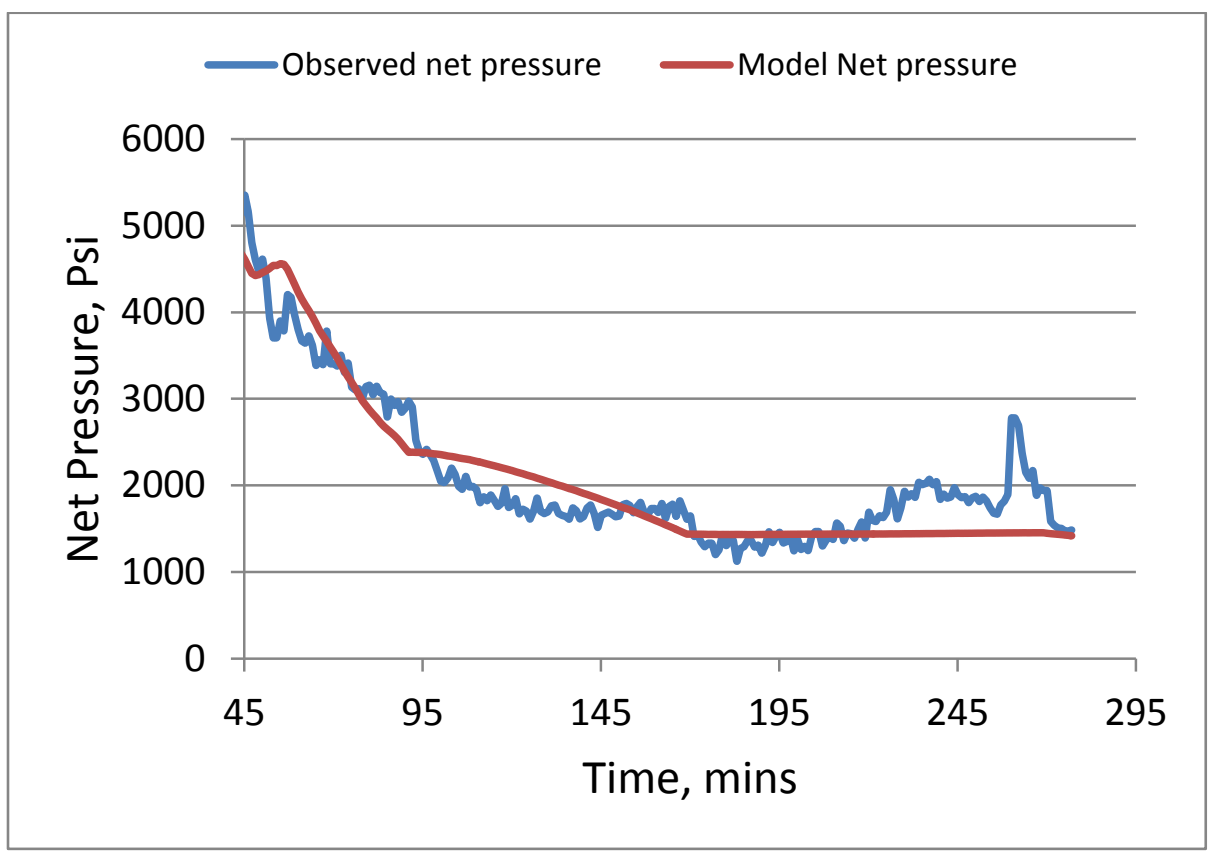

Figure 30 - Net pressure match for stage L1 
The high net pressures observed throughout the pad are not able to be matched without using the fracture complexity feature of Fracpro. Although complexity was added in the model to match the high pressures, the efficiency was maintained at about 90\%. This can be done within the complexity control panel of Fracpro. It is important to maintain a high efficiency in order to create a fracture profile which is plausible. A match can be obtained with large leak-off however this often results in much shorter half-lengths and wider fractures.

The match which is most similar to the microseismic geometry is presented in Figure 31. Despite maintaining fluid efficiency of above $90 \%$, the height and half-length obtained by the match were less than that seen in the microseismic. This suggests the possibility that the microseismic cloud is larger than the created fracture.

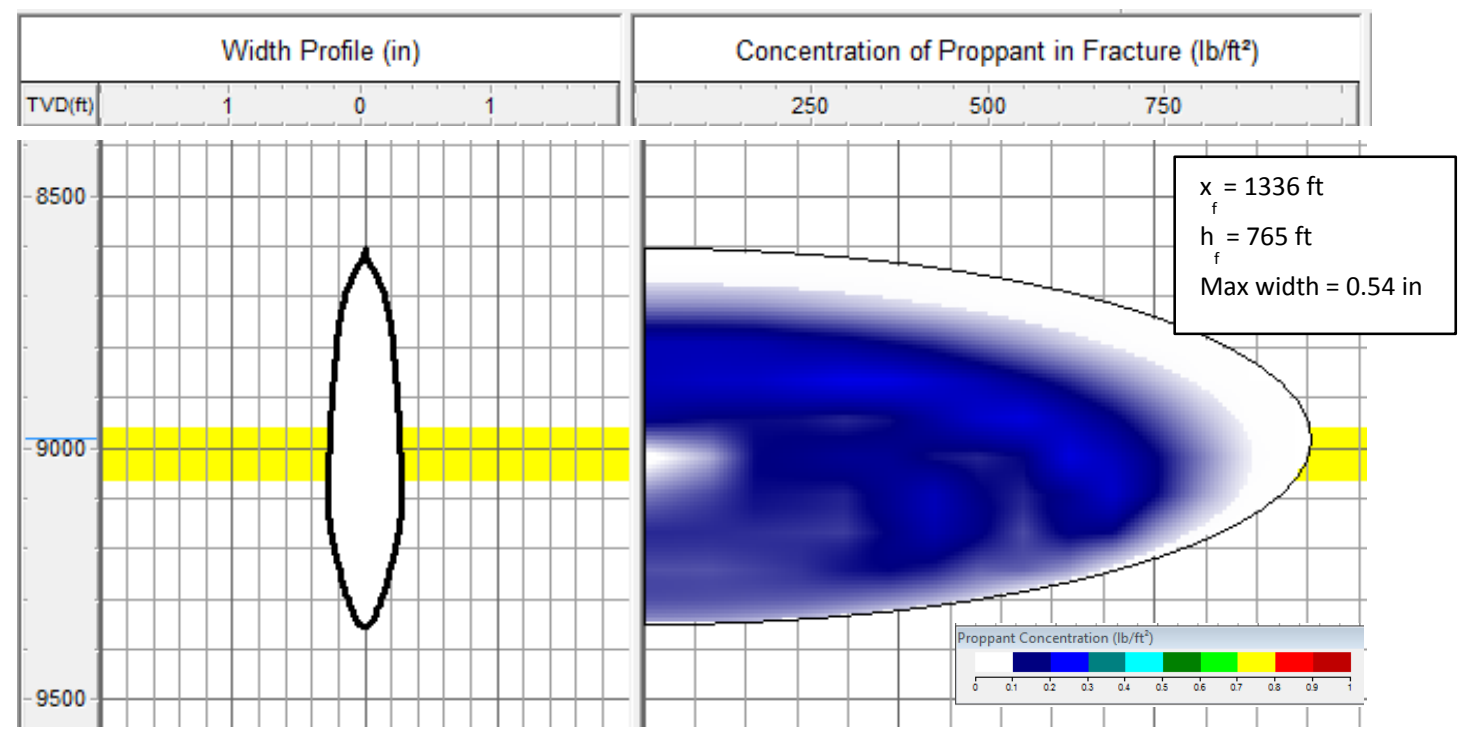

Figure 31 - fracture profile for stage L1 
The blue color represents the propped dimensions which are even smaller than the created fracture. The details of proppant placement will be discussed later on in the report.

Another treatment match for Stage J8 is shown in Figure 32.Although there is no microseismic data for stage $\mathrm{J} 8$, the net pressure match is presented to show similarity with stage L1. Although the overall trend was matched, the bumps in pressure could not be matched by the software.

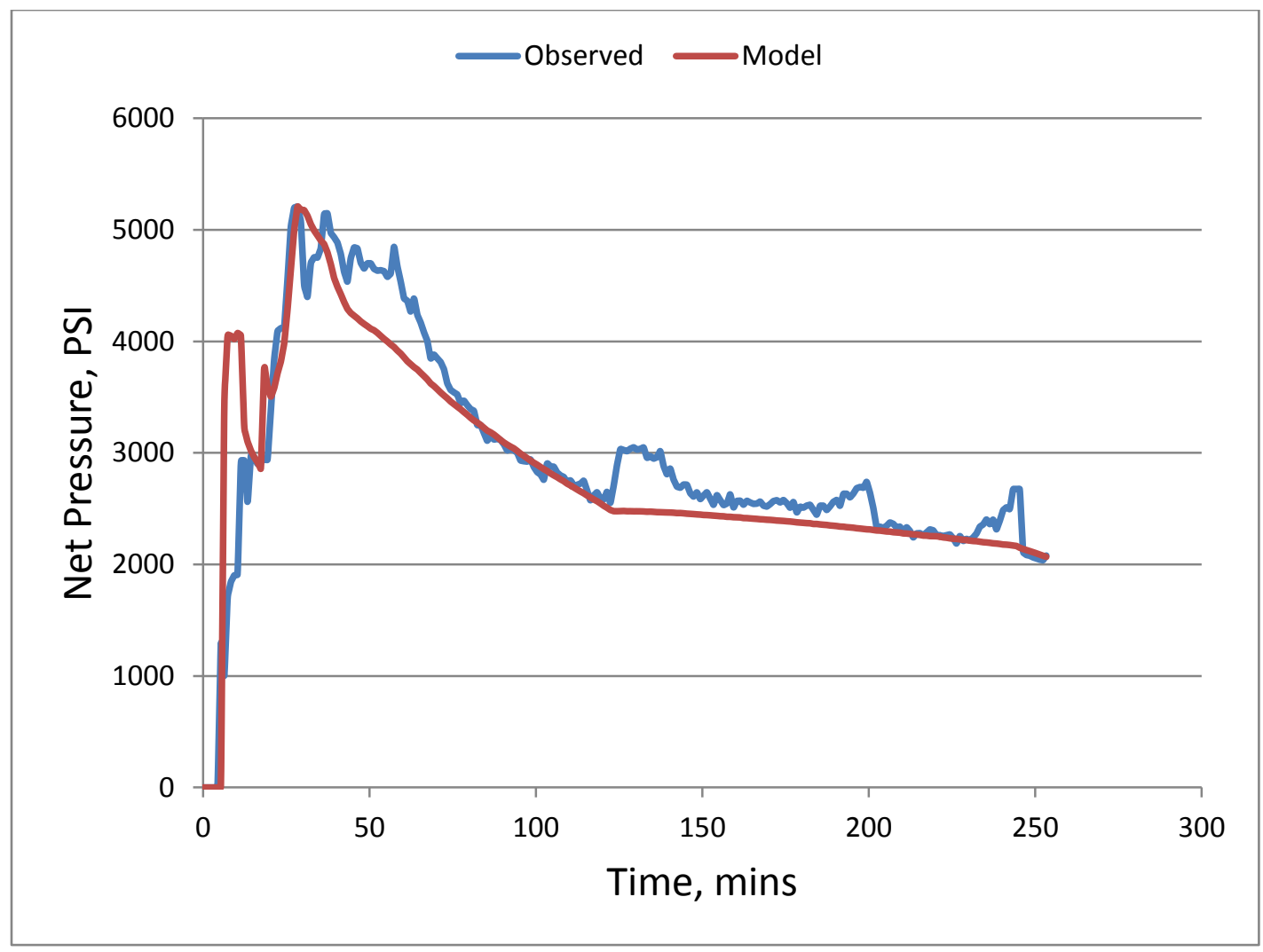

Figure 32 - Net pressure match of stage J8 


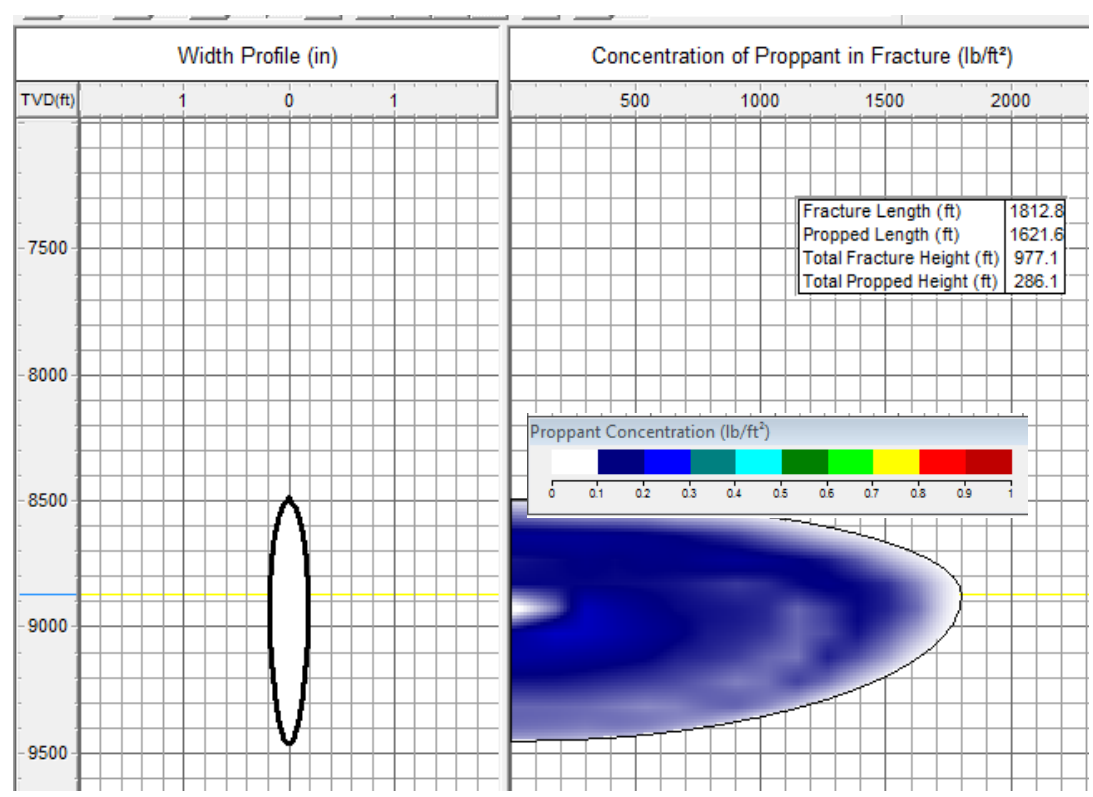

Figure 33 - Fracture profile, J8

The modeled fracture geometry of Stage J8 is presented in Figure 33. The geometry is similar to that observed in well L. Again the propped dimensions are significantly less than the initial created fracture dimensions. In both of these cases, the proppant concentration (color) is very low. There is also a lack of proppant next to the perforations which is due to a large overflush equivalent to about two and a half wellbore volumes that was pumped in all of the treatments.

The overflush technique is sometimes used by operators to clear the wellbore of proppant after completing the fracture treatment. If the wellbore is clear, the operator can avoid having to clean out any remaining fracture slurry with coiled-tubing. Although this does save the operator some money and rig time, the fracture may close at the 
perforations resulting in a large skin due to fracture choking. Proppant location will be discussed later on in the report.

Almost all of the stages showed the similar negative slope observed in wells $\mathbf{J}$ and D. A few of the stages however did not show a decrease in pressure. They showed a flat trend (slope $=0$ ) which Nolte-Smith identify as simultaneous height and length growth. One of these stages was A4. Well A is on the northeast periphery of the pad. Figure 34 shows the net pressure match for A4.

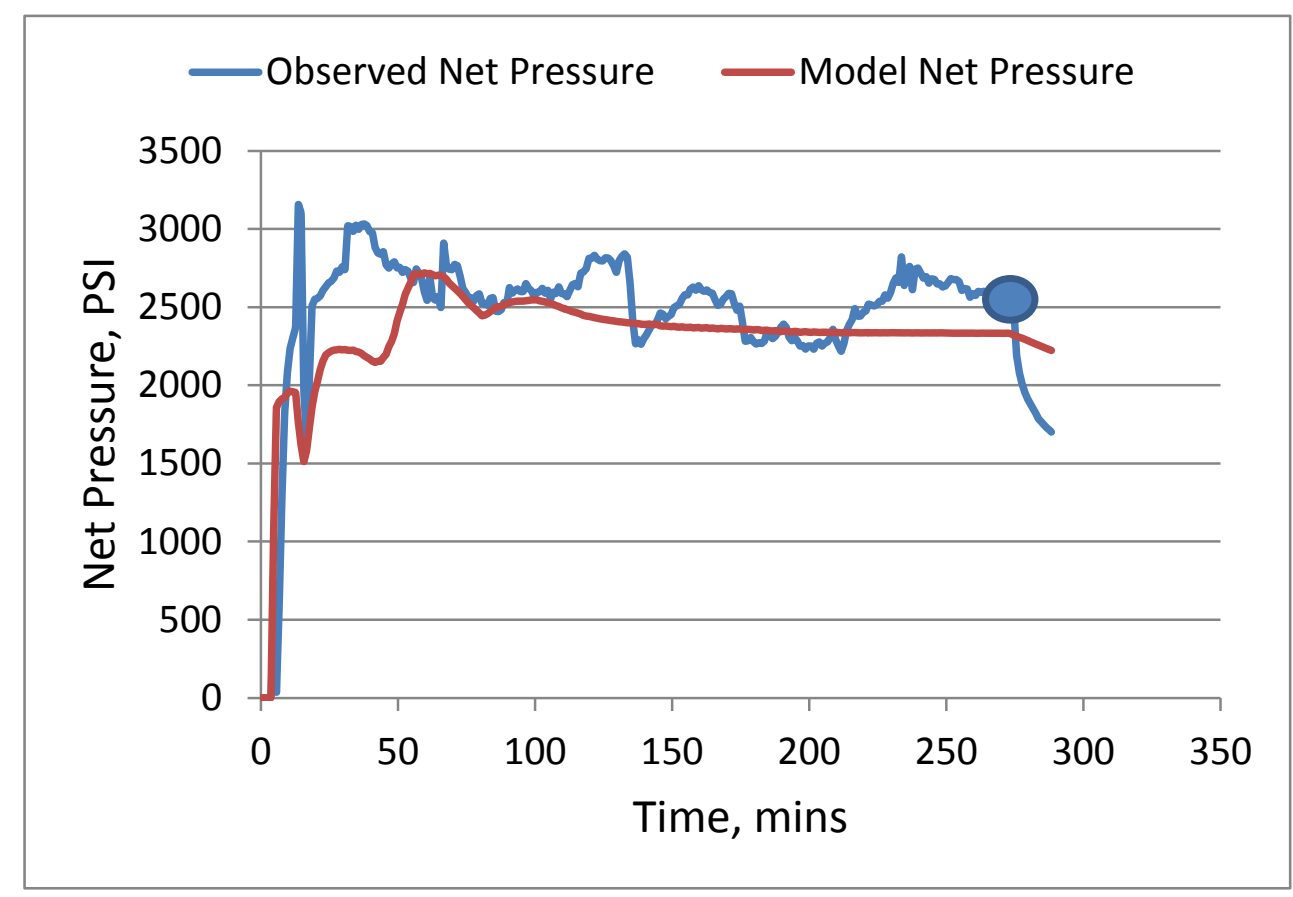

Figure 34 - Net pressure match stage A4

The match obtained for this stage assumed $90 \%$ fluid efficiency similar to all of the other stages. The negative slope however was not observed therefore the fracture half-length estimated from this match was larger than the other stages. Stage A4 was the 
only well where the treatment model resulted in a slightly larger fracture half-length than that predicted by microsiesmic. The geometry obtained from net pressure matching is shown in Figure 35. The fracture height from microseismic was $862 \mathrm{ft}$ and the halflength was $1584 \mathrm{ft}$.
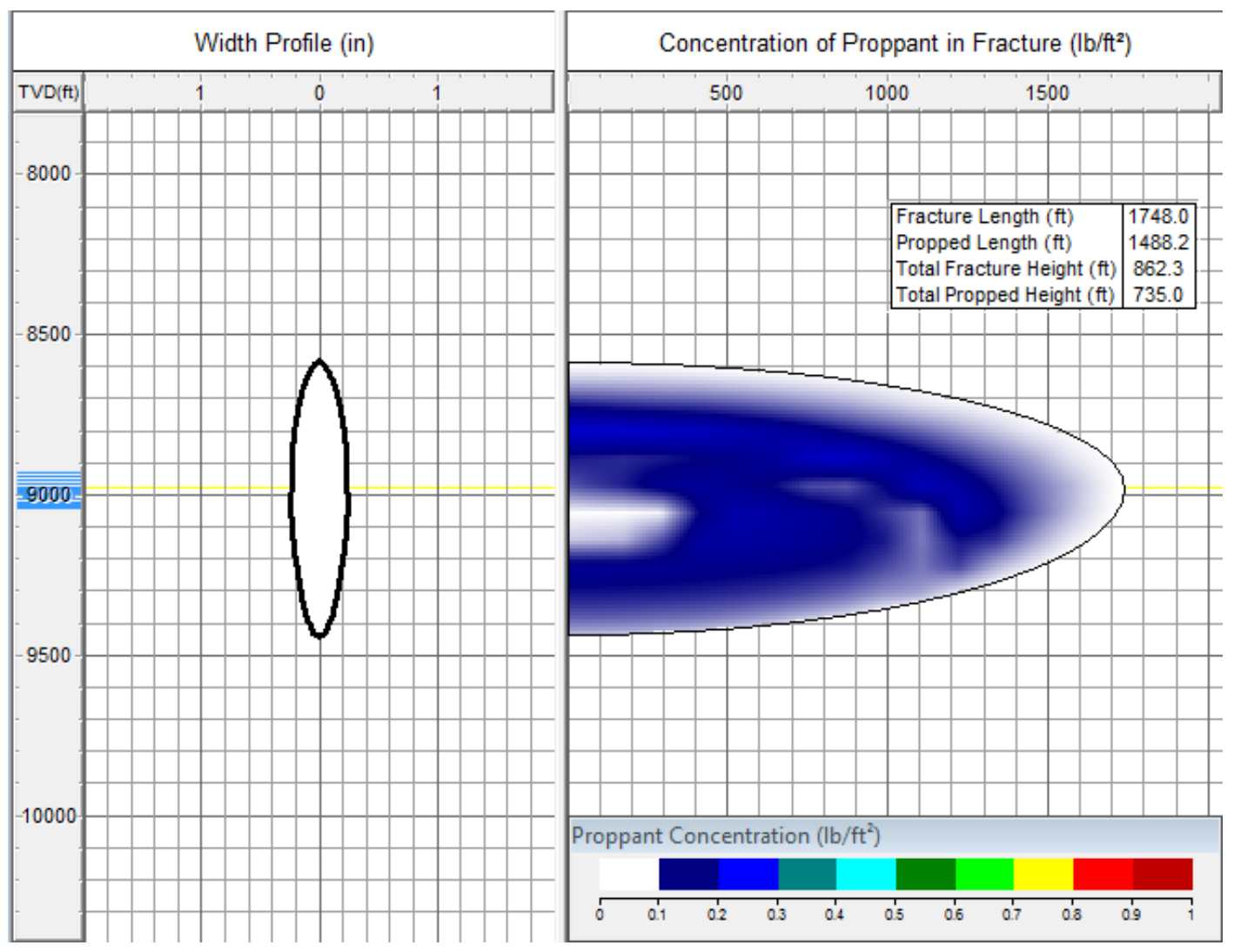

Figure 35 - Stage A4 fracture profile

\section{Irregular Growth}

As indicated in the microseimic chapter of the report, some of the stages were quite irregular. The net pressure of these irregular stages is presented here in order to identify any unusual trends that might be seen. 
Stage G3 was presented in the microseismic chapter showing asymmetric growth. It was postulated that there may be some conduit within the formation which is allowing the fracture to grow preferentially towards one side. Figure 36 is the net pressure plot stage G3.

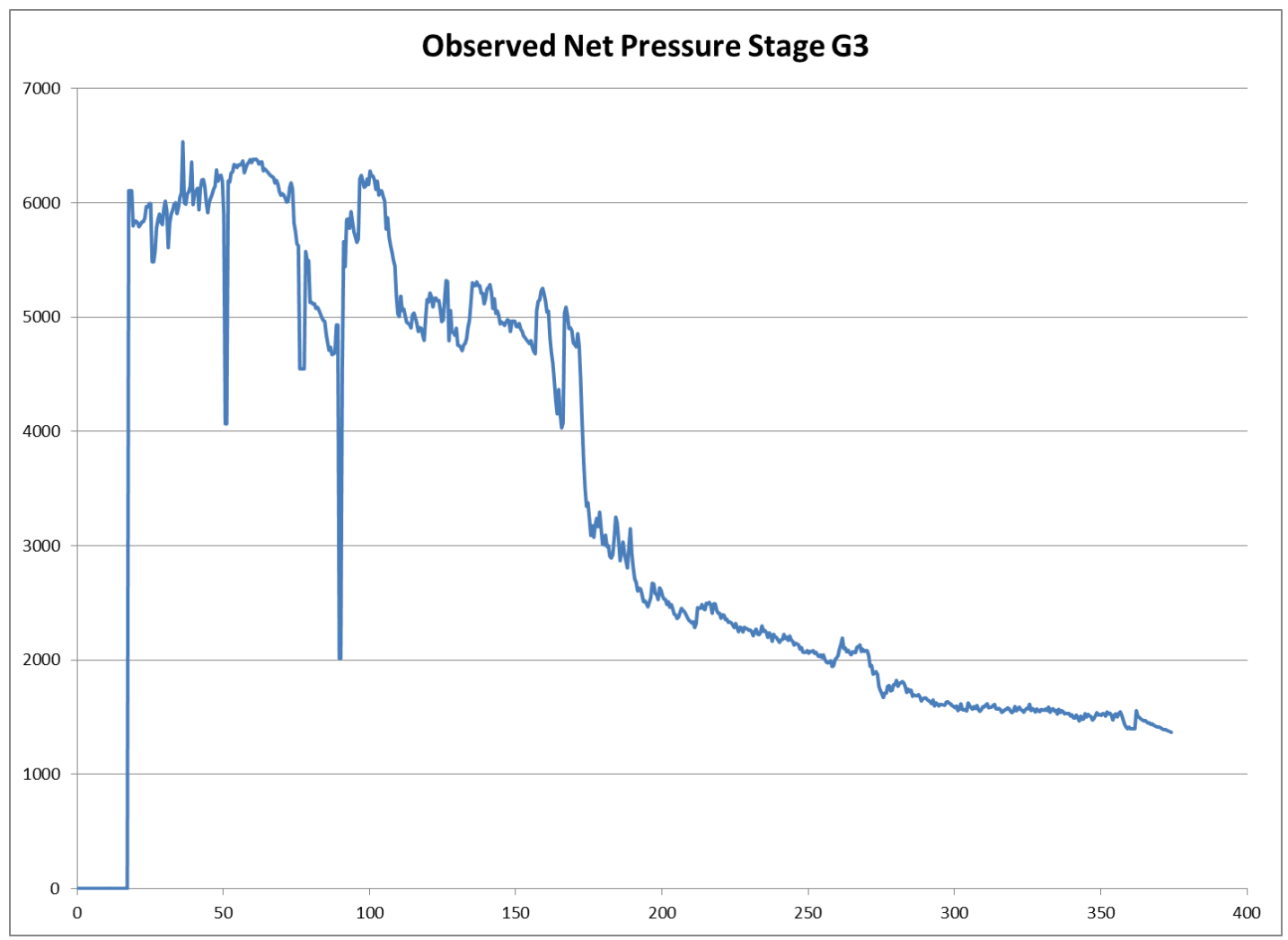

Figure 36 - Stage G3 observed net pressure

The microseismic for stage G3 showed balance fracture growth early on in the treatment. This is also seen in the net pressure for about the first 150 minutes of the treatment. After that, the net pressure decreases substantially. This is almost as if the 
fracture reached a conduit which allowed the fracture to propagate at much lower pressures.

The second unusual case discussed in the microseismic chapter was stage O5. In this stage the fracture started growing at a $45^{\circ}$ angle to the main fracture plain. This again would not have been possible if the fracture growth was only based on the formation stresses. The net pressure plot of stage O5 is seen in Figure 37.

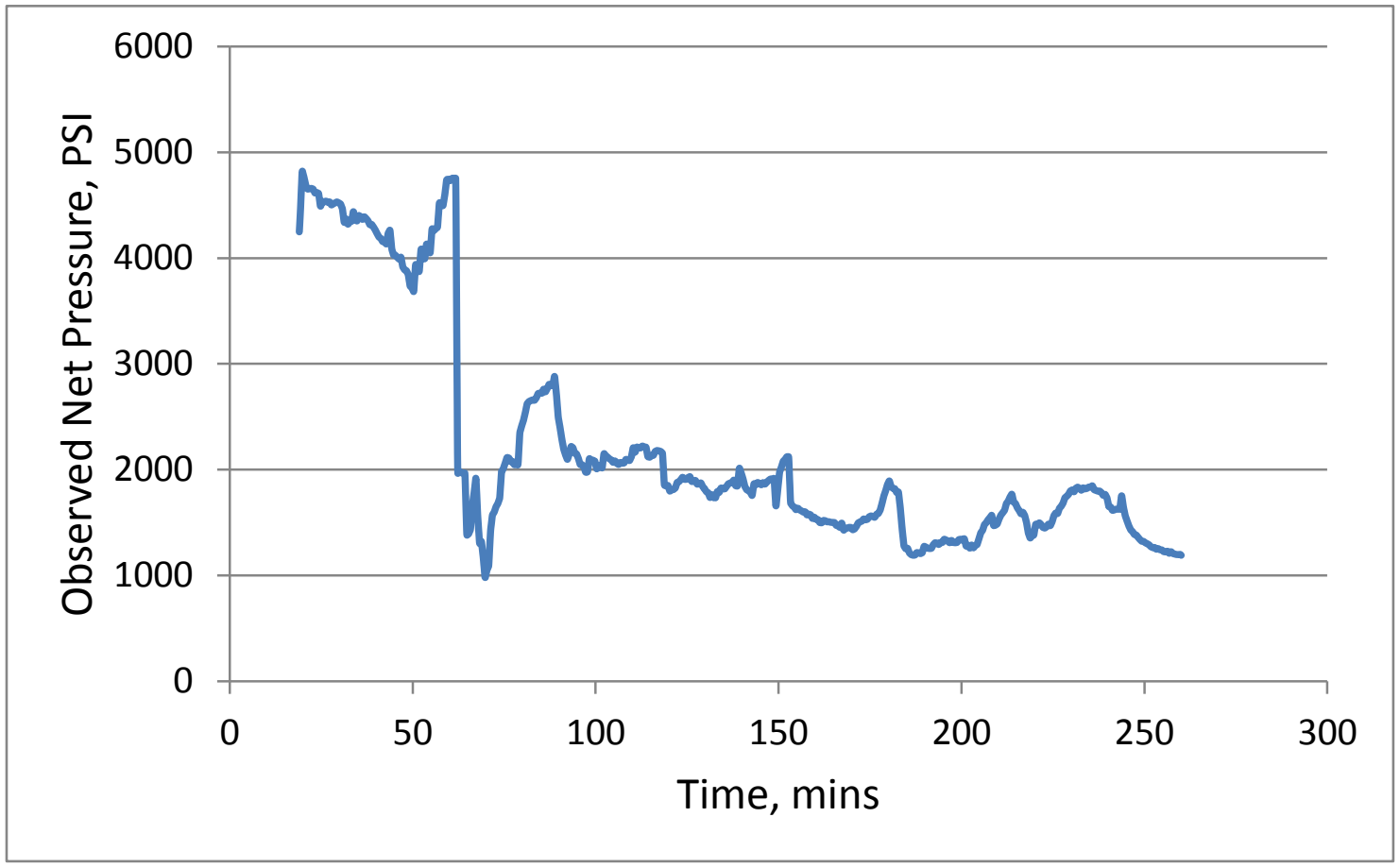

Figure 37 - Stage 05 net pressure 


\section{Proppant Location}

Perhaps one of the most interesting questions in regards to fracturing in shales is the location of the proppant. The majority of operators use both 100 mesh and 40/70 proppant. Conventionally, 100 mesh proppant is used as a fluid loss control agent. Many times operators use 100 mesh proppant as up to $50 \%$ of the total proppant.

FracproPT models proppant transport using convection. The software developers cite laboratory and computer simulations indicating that proppant convection may be a dominant mechanism in propped-fracture stimulations. The software also models proppant settling taking into account the effects of non-Newtonian fluids, hindered settling rates, and settled bank buildup.

Figures 38 and 39 show the location of proppant in stages J8 and A4 respectively. The red color is the 40/70 proppant and the green color is the 100 mesh sand. The white area next to the perforations contains no proppant because of the overflush. 


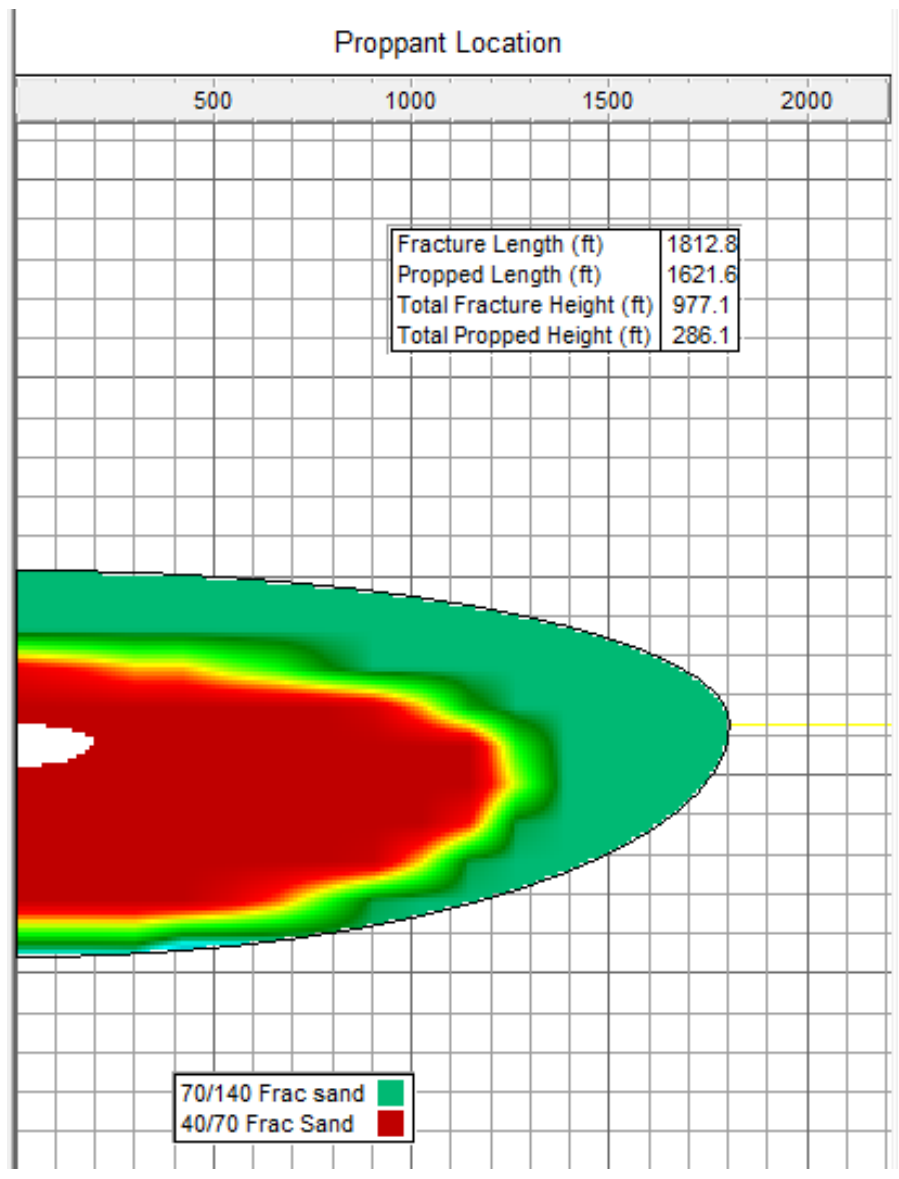

Figure 38 - Stage J8 proppant location 


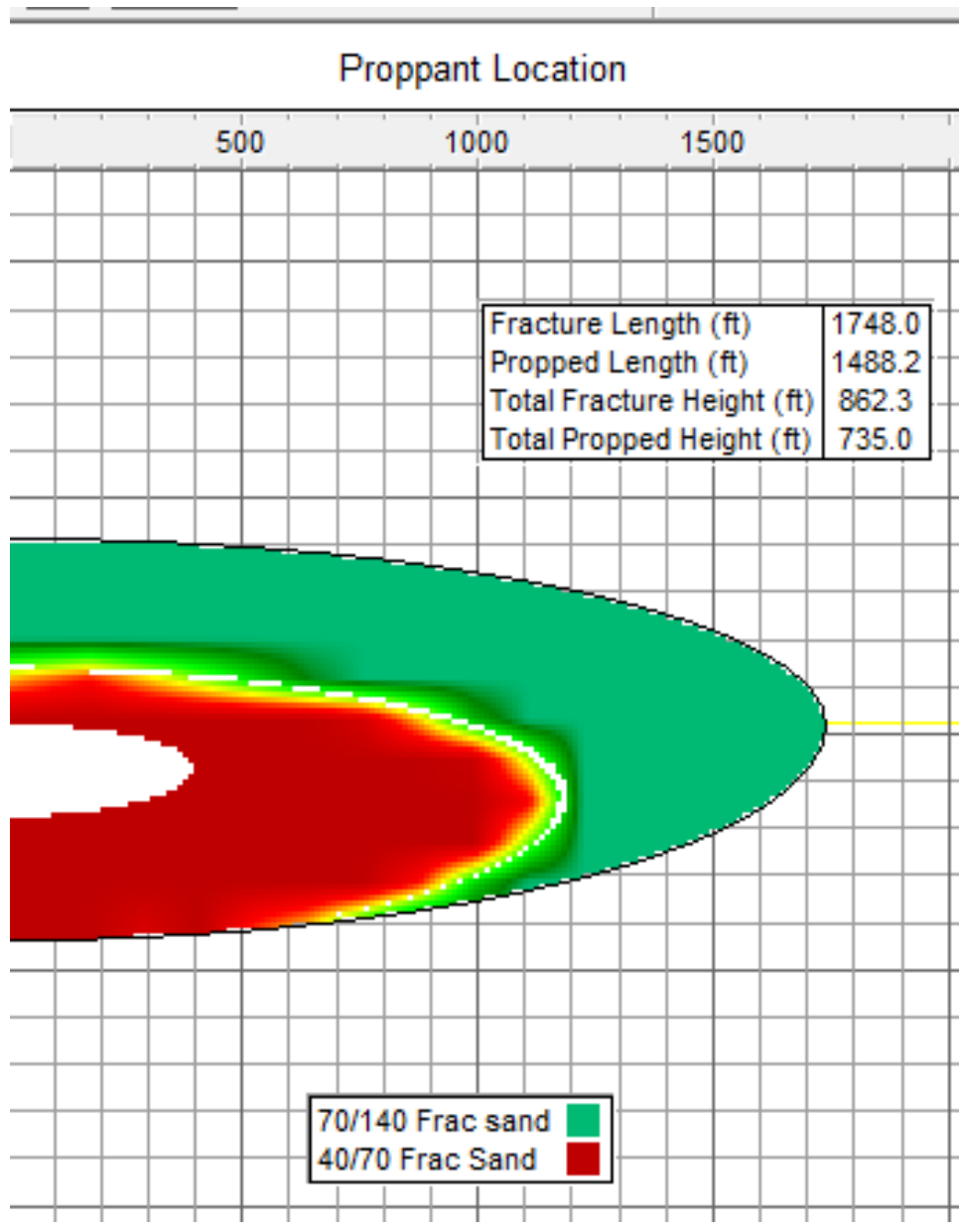

Figure 39 - Stage A4

As discussed earlier, the propped dimensions are smaller than the created fracture. If we assume that the portion of the fracture containing 100 mesh is also unproductive, we obtain a much shorter height and half length. These shorter halflengths would also be consistent with those estimated by PDA analysis conducted by Ehlig-Economides et al. (2012). 
Some of the operators using large amounts of 100 mesh proppant have stated that the reason for doing so is that the 100 mesh fills the natural fractures. This was also suggested by Warpinski (1987). Although the detail information regarding natural fractures in Horn River is unavailable, other more developed shale plays have much more information. The Barnett shale reportedly has cemented natural fractures that are reopened by shear dilation during hydraulic fracturing. Gale et. al stated that the maximum width of the natural fractures in the Barnett is 0.002 inches. The diameter of 100 mesh proppant is 0.0059 inches. The diameter of $40 / 70$ proppant ranges from 0.0083 inches to 0.0165 inches. This means that the natural fracture must dilate to at least 3 times the original size in order to be equivalent to the diameter of 100 mesh proppant. In order to avoid proppant bridging the actual width must be substantially larger the 100 mesh diameter. Due to these issues, it seems highly unlikely that either the 100 mesh or $40 / 70$ is being placed into the natural fractures.

\section{Chapter Summary}

Two major trends were observed in the net fracturing pressure, a negative slope followed by a flat trend (slope $=0$ ). These trends suggest that the fracture initially grows radially until it comes into contact with the fracture barriers after which it grows similar to the PKN model.

The proppant modeling illustrates that the fracture dimensions propped by 40/70 proppant are substantially smaller than the original fracture. Based on the size of the proppant, it is very unlikely that any proppant is being placed into the natural fractures. 
The post-treatment overflush also has the potential to choke the fracture resulting in increased skin. 


\section{CHAPTER V}

\section{CONCLUSIONS}

- The height growth observed by both microseismic and treatment modeling is sufficient to cover the entire payzone (Muskwa and Otterpark)

- The length observed in microseismic is about $15 \%$ larger than what is possible if material balance is honored

- The created fractures were transverse to the horizontal well

- The created fracture half-lengths are considerably larger than half the well spacing but the extent of 40/70 proppant may be only slightly larger

- Possible evidence of fracture complexity appears in the microseismic data

- Irregular fracture growth was seen in some of the stages by microseismic but it can also be diagnosed using the net pressure plot

- Overflush is resulting in choked fractures (increased skin)

- The actual propped dimensions (40/70) are much shorter than the original created fracture 


\section{REFERENCES}

Barree, R.D., Cox, S.A., Dobson, M.L. et al. 2005. Closing the Gap: Fracture HalfLength from Design, Buildup, and Production Analysis. SPE Production \& Operations 20 (4): pp. 274-285. SPE-84491-PA.

Beaudoin, W.P., Khalid, S., Allison, J. et al. 2011. Horn River Basin: A Study of the Behaviour of Frac Barriers in a Thick Shale Package Using the Integration of Microseismic, Geomechanics and Log Analysis. Paper presented at the Canadian Unconventional Resources Conference, Alberta, Canada. Society of Petroleum Engineers SPE-147510-MS.

Cipolla, C.L., Lolon, E., and Mayerhofer, M.J. 2009. Resolving Created, Propped, and Effective Hydraulic-Fracture Length. SPE Production \& Operations 24 (4): 619628. SPE-129618-PA.

Cipolla, C.L., Warpinski, N.R., Mayerhofer, M. et al. 2010. The Relationship between Fracture Complexity, Reservoir Properties, and Fracture-Treatment Design. SPE Production \& Operations 25 (4): pp. 438-452. SPE-115769-PA.

Davidson, B.M., Saunders, B.F., Robinson, B.M. et al. 1993. Analysis of Abnormally High Fracture Treating Pressures Caused by Complex Fracture Growth. Paper presented at the SPE Gas Technology Symposium, Calgary, Alberta, Canada. 1993 Copyright 1993, Society of Petroleum Engineers, Inc. 00026154.

Economides, M., Martin, T., 2008. Modern Fracturing: Energy Tribune Publishing Inc.

Ehlig-Economides, C.A., Ahmed, I.A., Apiwathanasorn, S. et al. 2012. Stimulated Shale Volume Characterization: Multiwell Case Study from the Horn River Shale: Ii. Flow Perspective. Paper presented at the SPE Annual Technical Conference and Exhibition, San Antonio, Texas, USA. Society of Petroleum Engineers SPE159546-MS.

Fisher, M.K., Heinze, J.R., Harris, C.D. et al. 2004. Optimizing Horizontal Completion Techniques in the Barnett Shale Using Microseismic Fracture Mapping. Paper presented at the SPE Annual Technical Conference and Exhibition, Houston, Texas. Society of Petroleum Engineers 00090051.

Gale, J. 2011. Fracture Propagation in Shales. In International Exposition and 81st Annual Meeting of the Society of Exploration Geophysicists. San Antonio, TX, USA: Society of Exploration Geophysicists.

Hurd, O. and Zoback, M.D. 2012. Stimulated Shale Volume Characterization: Multiwell Case Study from the Horn River Shale: I. Geomechanics and Microseismicity. 
Paper presented at the SPE Annual Technical Conference and Exhibition, San Antonio, Texas, USA. Society of Petroleum Engineers SPE-159536-MS.

Mohamed, I.M., Azmy, R.M., Sayed, M.A.I. et al. 2011. Evaluation of after-Closure Analysis Techniques for Tight and Shale Gas Formations. Paper presented at the SPE Hydraulic Fracturing Technology Conference, The Woodlands, Texas, USA. Society of Petroleum Engineers SPE-140136-MS.

Nolte, K.G. 1979. Determination of Fracture Parameters from Fracturing Pressure Decline. Paper presented at the SPE Annual Technical Conference and Exhibition, Las Vegas, Nevada. 1979 Copyright 1979 American Institute of Mining, Metallurgical, and Petroleum Engineers, Inc. 00008341.

Nolte, K.G. 1988. Principles for Fracture Design Based on Pressure Analysis. SPE Production Engineering 3 (1): 22-30. 00010911.

Song, B., Economides, M.J., and Ehlig-Economides, C.A. 2011. Design of Multiple Transverse Fracture Horizontal Wells in Shale Gas Reservoirs. Paper presented at the SPE Hydraulic Fracturing Technology Conference, The Woodlands, Texas, USA. Society of Petroleum Engineers SPE-140555-MS.

Warpinski, N.R. 1991. Hydraulic Fracturing in Tight, Fissured Media. SPE Journal of Petroleum Technology 43 (2): 146-151, 208-209. 00020154.

Warpinski, N.R. and Teufel, L.W. 1987. Influence of Geologic Discontinuities on Hydraulic Fracture Propagation (Includes Associated Papers 17011 and 17074 ). SPE Journal of Petroleum Technology 39 (2): 209-220. 00013224. 


\section{APPENDIX A}

\section{MODEL INPUTS}

Table 2: Input for Multiple Fractures feature stage L1A

\begin{tabular}{|c|c|c|c|}
\hline Time, mins & Volume Factor & Leakoff Factor & Opening factor \\
\hline 0 & 1 & 1 & 50 \\
\hline 90 & 1 & 1 & 12 \\
\hline 168 & 1 & 1 & 5 \\
\hline $1,000.00$ & 1 & 1 & 3 \\
\hline
\end{tabular}

Table 3: Input for Multiple Fractures feature stage J8

\begin{tabular}{|c|c|c|c|}
\hline Time, mins & Volume Factor & Leakoff factor & Opening factor \\
\hline 0 & 1 & 1 & 65 \\
\hline 122 & 1 & 1 & 30 \\
\hline 245 & 1 & 1 & 25 \\
\hline $10,000.00$ & 1 & 1 & 5 \\
\hline
\end{tabular}

Table 4: Input Multiple Fractures feature stage A4

\begin{tabular}{|c|c|c|c|}
\hline Time, mins & Volume factor & Leakoff factor & Opening factor \\
\hline 0 & 1 & 1 & 10 \\
\hline $10,000.00$ & 1 & 1 & 1 \\
\hline
\end{tabular}

Table 5: Lithology Inputs used for fracture model

\begin{tabular}{|c|c|c|c|c|c|}
\hline $\begin{array}{l}\text { Depth, } \\
\text { TVD }\end{array}$ & $\begin{array}{l}\text { Depth } \\
\text { MD }\end{array}$ & $\begin{array}{c}\text { Stress } \\
\text { Gradient }\end{array}$ & $\begin{array}{l}\text { Young's } \\
\text { Modulus }\end{array}$ & $\begin{array}{l}\text { Poisson's } \\
\text { Ratio }\end{array}$ & $\begin{array}{c}\text { Fracture } \\
\text { Toughness }\end{array}$ \\
\hline $\mathrm{ft}$ & $\mathrm{ft}$ & $(\mathrm{psi} / \mathrm{ft})$ & psi & - & $\left(\mathrm{psi} \cdot \mathrm{in}^{1 / 2}\right)$ \\
\hline 0 & 0 & 1.157 & $4.61 \mathrm{E}+06$ & 0.25 & $1,638.10$ \\
\hline $8,639.40$ & $8,784.10$ & 0.652 & $4.61 \mathrm{E}+06$ & 0.25 & $1,569.70$ \\
\hline $8,646.00$ & $8,791.60$ & 0.657 & $4.54 \mathrm{E}+06$ & 0.252 & $1,475.60$ \\
\hline $8,652.50$ & $8,799.10$ & 0.655 & $4.55 \mathrm{E}+06$ & 0.251 & $1,269.30$ \\
\hline $8,659.10$ & $8,806.60$ & 0.663 & $4.51 \mathrm{E}+06$ & 0.255 & $1,831.40$ \\
\hline $8,665.60$ & $8,814.10$ & 0.661 & $4.45 \mathrm{E}+06$ & 0.255 & $1,369.90$ \\
\hline $8,672.20$ & $8,821.60$ & 0.66 & $4.52 \mathrm{E}+06$ & 0.253 & $1,368.40$ \\
\hline $8,678.80$ & $8,829.10$ & 0.648 & $4.62 \mathrm{E}+06$ & 0.248 & $1,597.20$ \\
\hline
\end{tabular}

62 


\begin{tabular}{|c|c|c|c|c|c|}
\hline $8,685.30$ & $8,836.60$ & 0.65 & $4.55 \mathrm{E}+06$ & 0.25 & $1,440.50$ \\
\hline $8,691.90$ & $8,844.00$ & 0.67 & $4.42 \mathrm{E}+06$ & 0.258 & $1,478.60$ \\
\hline $8,698.50$ & $8,851.60$ & 0.686 & $4.12 \mathrm{E}+06$ & 0.264 & $1,812.90$ \\
\hline $8,705.00$ & $8,859.20$ & 0.671 & $4.30 \mathrm{E}+06$ & 0.259 & $1,353.40$ \\
\hline $8,711.60$ & $8,866.80$ & 0.672 & $4.35 \mathrm{E}+06$ & 0.259 & $1,306.40$ \\
\hline $8,718.10$ & $8,874.40$ & 0.671 & $4.28 \mathrm{E}+06$ & 0.258 & $1,527.60$ \\
\hline $8,724.70$ & $8,882.10$ & 0.651 & $4.65 \mathrm{E}+06$ & 0.247 & $1,145.20$ \\
\hline $8,731.30$ & $8,889.70$ & 0.648 & $4.50 \mathrm{E}+06$ & 0.249 & 912 \\
\hline $8,737.80$ & $8,897.40$ & 0.647 & $4.59 \mathrm{E}+06$ & 0.247 & 993.6 \\
\hline $8,744.40$ & $8,905.20$ & 0.653 & $4.55 \mathrm{E}+06$ & 0.249 & 927 \\
\hline $8,751.00$ & $8,913.10$ & 0.648 & $4.66 \mathrm{E}+06$ & 0.245 & 814.9 \\
\hline $8,757.50$ & $8,920.90$ & 0.672 & $4.26 \mathrm{E}+06$ & 0.259 & $1,559.60$ \\
\hline $8,764.10$ & $8,928.80$ & 0.678 & $4.14 \mathrm{E}+06$ & 0.262 & $1,663.70$ \\
\hline $8,770.60$ & $8,936.70$ & 0.651 & $4.55 \mathrm{E}+06$ & 0.247 & $1,010.60$ \\
\hline $8,777.20$ & $8,944.60$ & 0.642 & $4.58 \mathrm{E}+06$ & 0.241 & $1,141.10$ \\
\hline $8,783.80$ & $8,952.80$ & 0.655 & $4.39 \mathrm{E}+06$ & 0.249 & $1,293.40$ \\
\hline $8,790.30$ & $8,961.00$ & 0.641 & $4.79 \mathrm{E}+06$ & 0.238 & 689.7 \\
\hline $8,796.90$ & $8,969.20$ & 0.652 & $4.50 \mathrm{E}+06$ & 0.247 & $1,249.30$ \\
\hline $8,803.40$ & $8,977.40$ & 0.663 & $4.28 \mathrm{E}+06$ & 0.254 & $1,392.50$ \\
\hline $8,810.00$ & $8,985.60$ & 0.72 & $3.42 \mathrm{E}+06$ & 0.284 & $2,002.10$ \\
\hline $8,816.60$ & $8,993.90$ & 0.75 & $2.76 \mathrm{E}+06$ & 0.306 & $2,002.10$ \\
\hline $8,823.10$ & $9,002.60$ & 0.705 & $3.84 \mathrm{E}+06$ & 0.273 & $2,002.10$ \\
\hline $8,829.70$ & $9,011.20$ & 0.712 & $3.53 \mathrm{E}+06$ & 0.279 & $2,002.10$ \\
\hline $8,836.30$ & $9,019.80$ & 0.674 & $4.17 \mathrm{E}+06$ & 0.258 & $1,526.60$ \\
\hline $8,842.80$ & $9,028.40$ & 0.647 & $4.56 \mathrm{E}+06$ & 0.242 & $1,165.20$ \\
\hline $8,849.40$ & $9,037.10$ & 0.652 & $4.51 \mathrm{E}+06$ & 0.244 & $1,197.30$ \\
\hline $8,855.90$ & $9,046.20$ & 0.65 & $4.63 \mathrm{E}+06$ & 0.241 & $1,155.20$ \\
\hline $8,862.50$ & $9,055.40$ & 0.649 & $4.47 \mathrm{E}+06$ & 0.244 & $1,194.30$ \\
\hline $8,869.10$ & $9,064.50$ & 0.709 & $3.72 \mathrm{E}+06$ & 0.276 & $2,002.10$ \\
\hline $8,875.60$ & $9,073.60$ & 0.671 & $4.28 \mathrm{E}+06$ & 0.256 & $1,441.50$ \\
\hline $8,882.20$ & $9,082.80$ & 0.68 & $4.13 \mathrm{E}+06$ & 0.261 & $1,621.70$ \\
\hline $8,888.70$ & $9,092.60$ & 0.653 & $4.40 \mathrm{E}+06$ & 0.246 & $1,238.30$ \\
\hline $8,895.30$ & $9,102.50$ & 0.635 & $4.65 \mathrm{E}+06$ & 0.234 & $1,078.70$ \\
\hline $8,901.90$ & $9,112.30$ & 0.63 & $4.78 \mathrm{E}+06$ & 0.231 & 955.2 \\
\hline $8,908.40$ & $9,122.20$ & 0.697 & $3.83 \mathrm{E}+06$ & 0.267 & $2,002.10$ \\
\hline $8,915.00$ & $9,132.50$ & 0.719 & $3.32 \mathrm{E}+06$ & 0.284 & $2,002.10$ \\
\hline $8,921.60$ & $9,143.30$ & 0.726 & $3.13 \mathrm{E}+06$ & 0.289 & $2,002.10$ \\
\hline $8,928.10$ & $9,154.20$ & 0.676 & $4.07 \mathrm{E}+06$ & 0.26 & $1,604.70$ \\
\hline $8,934.70$ & $9,165.00$ & 0.722 & $3.25 \mathrm{E}+06$ & 0.286 & $2,002.10$ \\
\hline $8,941.20$ & $9,175.80$ & 0.717 & $3.36 \mathrm{E}+06$ & 0.282 & $2,002.10$ \\
\hline $8,947.80$ & $9,187.80$ & 0.684 & $4.01 \mathrm{E}+06$ & 0.263 & $1,756.80$ \\
\hline $8,954.40$ & $9,200.00$ & 0.733 & $2.96 \mathrm{E}+06$ & 0.294 & $2,002.10$ \\
\hline
\end{tabular}




\begin{tabular}{|c|c|c|c|c|c|}
$8,960.90$ & $9,212.10$ & 0.726 & $6.00 \mathrm{E}+06$ & 0.289 & $2,002.10$ \\
\hline $8,967.50$ & $9,224.90$ & 0.77 & $6.00 \mathrm{E}+06$ & 0.319 & $2,002.10$ \\
\hline $8,974.00$ & $9,239.00$ & 0.652 & $6.00 \mathrm{E}+06$ & 0.252 & $1,345.40$ \\
\hline $8,980.60$ & $9,253.10$ & 0.696 & $6.00 \mathrm{E}+06$ & 0.257 & $1,481.60$ \\
\hline $8,987.20$ & $14,346.10$ & 0.643 & $6.00 \mathrm{E}+06$ & 0.242 & $1,174.20$ \\
\hline $8,993.70$ & $13,886.80$ & 0.649 & $6.00 \mathrm{E}+06$ & 0.247 & $1,245.30$ \\
\hline $9,000.30$ & $13,212.70$ & 0.738 & $6.00 \mathrm{E}+06$ & 0.297 & $2,002.10$ \\
\hline $9,006.90$ & $12,822.90$ & 0.801 & $6.00 \mathrm{E}+06$ & 0.339 & $2,002.10$ \\
\hline $9,013.40$ & $12,548.50$ & 0.665 & $6.00 \mathrm{E}+06$ & 0.253 & $1,364.40$ \\
\hline $9,020.00$ & $12,269.20$ & 0.721 & $6.00 \mathrm{E}+06$ & 0.285 & $2,002.10$ \\
\hline $9,026.50$ & $11,974.40$ & 0.637 & $6.00 \mathrm{E}+06$ & 0.23 & 735.7 \\
\hline $9,033.10$ & $11,680.20$ & 0.698 & $6.00 \mathrm{E}+06$ & 0.268 & $2,002.10$ \\
\hline $9,039.70$ & $11,422.50$ & 0.681 & $6.00 \mathrm{E}+06$ & 0.262 & $1,699.80$ \\
\hline $9,046.20$ & $11,013.40$ & 0.676 & $6.00 \mathrm{E}+06$ & 0.26 & $1,596.70$ \\
\hline $9,052.80$ & $10,499.10$ & 0.65 & $6.00 \mathrm{E}+06$ & 0.243 & 843.9 \\
\hline $9,059.40$ & $10,164.10$ & 0.642 & $6.00 \mathrm{E}+06$ & 0.238 & 826.6 \\
\hline
\end{tabular}

Barree, R.D., Cox, S.A., Dobson, M.L. et al. 2005. Closing the Gap: Fracture HalfLength from Design, Buildup, and Production Analysis. SPE Production \& Operations 20 (4): pp. 274-285. SPE-84491-PA.

Beaudoin, W.P., Khalid, S., Allison, J. et al. 2011. Horn River Basin: A Study of the Behaviour of Frac Barriers in a Thick Shale Package Using the Integration of Microseismic, Geomechanics and Log Analysis. Paper presented at the Canadian Unconventional Resources Conference, Alberta, Canada. Society of Petroleum Engineers SPE-147510-MS.

Cipolla, C.L., Lolon, E., and Mayerhofer, M.J. 2009. Resolving Created, Propped, and Effective Hydraulic-Fracture Length. SPE Production \& Operations 24 (4): 619628. SPE-129618-PA.

Cipolla, C.L., Warpinski, N.R., Mayerhofer, M. et al. 2010. The Relationship between Fracture Complexity, Reservoir Properties, and Fracture-Treatment Design. SPE Production \& Operations 25 (4): pp. 438-452. SPE-115769-PA.

Davidson, B.M., Saunders, B.F., Robinson, B.M. et al. 1993. Analysis of Abnormally High Fracture Treating Pressures Caused by Complex Fracture Growth. Paper presented at the SPE Gas Technology Symposium, Calgary, Alberta, Canada. 1993 Copyright 1993, Society of Petroleum Engineers, Inc. 00026154. 
Gale, J. 2011. Fracture Propagation in Shales. In International Exposition and 81st Annual Meeting of the Society of Exploration Geophysicists. San Antonio, TX, USA: Society of Exploration Geophysicists.

Mohamed, I.M., Azmy, R.M., Sayed, M.A.I. et al. 2011. Evaluation of after-Closure Analysis Techniques for Tight and Shale Gas Formations. Paper presented at the SPE Hydraulic Fracturing Technology Conference, The Woodlands, Texas, USA. Society of Petroleum Engineers SPE-140136-MS.

Nolte, K.G. 1979. Determination of Fracture Parameters from Fracturing Pressure Decline. Paper presented at the SPE Annual Technical Conference and Exhibition, Las Vegas, Nevada. 1979 Copyright 1979 American Institute of Mining, Metallurgical, and Petroleum Engineers, Inc. 00008341.

Nolte, K.G. 1988. Principles for Fracture Design Based on Pressure Analysis. SPE Production Engineering 3 (1): 22-30. 00010911.

Song, B., Economides, M.J., and Ehlig-Economides, C.A. 2011. Design of Multiple Transverse Fracture Horizontal Wells in Shale Gas Reservoirs. Paper presented at the SPE Hydraulic Fracturing Technology Conference, The Woodlands, Texas, USA. Society of Petroleum Engineers SPE-140555-MS.

Warpinski, N.R. 1991. Hydraulic Fracturing in Tight, Fissured Media. SPE Journal of Petroleum Technology 43 (2): 146-151, 208-209. 00020154.

Warpinski, N.R. and Teufel, L.W. 1987. Influence of Geologic Discontinuities on Hydraulic Fracture Propagation (Includes Associated Papers 17011 and 17074 ). SPE Journal of Petroleum Technology 39 (2): 209-220. 00013224. 